\title{
Oligomerization of Monoolefins by Homogeneous Catalysts
}

\author{
A. Forestière, H. Olivier-Bourbigou and L. Saussine \\ Institut français du pétrole, IFP-Lyon, BP 3, 69360 Solaize - France \\ e-mail: alain.forestiere@ifp.fr - helene.olivier-bourbigou@ifp.fr - lucien.saussine@ifp.fr
}

\begin{abstract}
Résumé - Oligomérisation des mono-oléfines par des catalyseurs homogènes - Cet article résume les différents schémas réactionnels pour l'oligomérisation des mono-oléfines par catalyse homogène, en particulier pour l'oligomérisation de l'éthylène et des alpha-oléfines. Les principaux sujets abordés sont la production régiosélective ou non de dimères, la production d'alpha-oléfines linéaires par oligomérisation de l'éthylène ainsi que la dimérisation sélective de l'éthylène et sa trimérisation sélective. Plusieurs procédés industriels développés par l'IFP sont présentés pour illustrer ce sujet.
\end{abstract}

Abstract - Oligomerization of Monoolefins by Homogeneous Catalysts - In this article are
summarized the different mechanistic pathways for the oligomerization of monoolefins by
homogeneous catalysts, particularly for ethylene and alpha olefins. The major topics are: the
production of non regioselective and also regioselective olefin dimers, the production of linear alpha
olefins by ethylene oligomerization as well as the selective dimerization of ethylene and its selective
trimerization. Several industrial developments initiated by IFP are presented to illustrate this topic. 


\section{INTRODUCTION}

The two main cracking processes of the refining and petrochemical industries - Fluid Catalytic Cracking (FCC) and Steam Cracking - produce important quantities of light olefinic fractions (having two to six carbon atoms) respectively as co products of gasoline for the FCC process, and as co-products of ethylene and propylene for the Steam Cracking process. Fischer-Tropsch (F-T) processes based on coal (CTL) or gas (GTL) produce a wide range of products, in terms of carbon number and class of compounds. Among those, short chain linear olefins $\left(\mathrm{C}_{2}-\mathrm{C}_{4}\right.$ olefins, $\mathrm{LPG}$ and $\mathrm{C}_{5}-\mathrm{C}_{9}$ olefins, naphta) can be one of the major products depending on the technology (catalyst type and operating conditions).

The oligomerization of monoolefins offers an attractive way for upgrading these light olefins either to produce fuel components (gasoline and/or middle distillates) or as intermediates for the manufacture of many type of products in the petrochemical industry. A considerable number of studies have been carried out on olefin oligomerization to improve both the activity and the selectivity for the desired compounds, in order to meet the commercial demand.

The oligomerization of monoolefins is still currently achieved with acidic catalysts, sometimes as liquids but mainly as solid acids (such as solid phosphoric acid SPA), and more recent approaches have looked at using mesoporous materials and specially designed acidic zeolithes [1]. However, the use of these acidic catalytic systems remains limited to only a few specific applications, in particular for the production of fuels. Due to their cationic reactivity, the main drawbacks of acid catalysts is their high deactivation rate [2], their poor selectivity and their low activity toward linear olefins.

In contrast homogeneous organometallic catalysts offer a broader spectrum of activity and more diversified selectivities. With an appropriate choice of metal-ligand and metal activator combination, it is possible to selectively obtain oligomers instead of high molecular weight polymers [3]. The regioselectivity of homogeneous catalysts can be tuned, such as the regioselective dimerization of propene to give 2,3-dimethylbutenes, 4-methyl-1-pentene or 2-methyl-1pentene. With a proper selection of the couples metal-ligand and metal-activators, it is possible to achieve either the selective dimerization of ethylene or its trimerization or even the tetramerization [4] associated with the trimerization of ethylene. Finally, thanks to the use of iron bis-iminopyridine complexes activated with aluminoxane, the dimerization of alpha olefins $\left(\mathrm{C}_{3}\right.$ to $\left.\mathrm{C}_{8}\right)$ to linear dimers, which is known to be difficult, has been recently improved [5-7].

Today the oligomerization of ethylene is the predominant route to linear alpha olefins.

Since the first industrial oligomerization processes, called full range processes, producing a wide range of even numbered linear alpha olefins [8] ranging from $\mathrm{C}_{4}$ to $\mathrm{C}_{30}$, significant progress has been made, in recent years, for selective oligomerization of ethylene into shorter distributions of alpha olefins or even into a main product (1-butene or 1-hexene by "on purpose" processes). Because the demand for linear alpha olefins is growing faster in the $\mathrm{C}_{4}-\mathrm{C}_{10}$ range than in the $\mathrm{C}_{12}{ }^{+}$range (see Tab. 1, 2), the selective formation of light alpha olefins from ethylene has been an important topic for academic and industrial research during the last twenty years.

TABLE 1

Market survey of alpha-olefins production

\begin{tabular}{l|c|c|c}
\hline & $\begin{array}{c}\text { Linear Alpha } \\
\text { Olefin (LAO) }\end{array}$ & 1-butene & 1-hexene \\
\hline Demand 2006 (Mt) & 4.3 & 1.1 & 0.650 \\
\hline $\begin{array}{l}\text { Estimated average } \\
\text { annual growing }\end{array}$ & $2006-2020$ & $2006-2020$ & $2006-2020$ \\
\hline $\begin{array}{l}\text { Production }(A A G R)(\%) \\
\text { Product }\end{array}$ & $\begin{array}{c}90 \% \text { of the } \\
\text { production by } \\
\text { ethylene } \\
\text { oligomerization }\end{array}$ & $\begin{array}{c}35 \% \text { of the } \\
\text { production by } \\
\text { ethylene } \\
\text { dimerization }\end{array}$ & $\begin{array}{c}\text { less than } 10 \% \\
\text { by ethylene } \\
\text { trimerization }\end{array}$ \\
\hline
\end{tabular}

The lighter alpha-olefins, 1-butene and 1-hexene, are mainly used as co-monomers for the manufacture of polyethylene (LLDPE and HDPE respectively 60\% and 20\% of the total demand of 1-butene and $60 \%$ and $30 \%$ of the total demand of 1-hexene).

TABLE 2

Breakdown of the main uses of alpha-olefins

\begin{tabular}{c|c|c|l}
\hline $\begin{array}{c}\text { Polyethylene co-monomer } \\
\mathrm{C}_{4}-\mathrm{C}_{8}\end{array}$ & $\begin{array}{c}\text { Oxo alcohols } \\
\mathrm{C}_{6}-\mathrm{C}_{16}\end{array}$ & $\begin{array}{c}\text { Poly alpha olefins } \\
\mathrm{C}_{10}-\mathrm{C}_{14}\end{array}$ & others \\
\hline $40 \%$ & $19 \%$ & $14 \%$ & $27 \%$ \\
\hline
\end{tabular}

In this article, we discuss the different mechanistic pathways for monoolefin oligomerization by homogeneous catalysts, particularly for ethylene and alpha olefins. The major topics are: the production of non regioselective and also regioselective olefin dimers, the production of linear alpha olefins by ethylene oligomerization as well as the dimerization and the trimerization of ethylene. Several industrial developments initiated by IFP will be reviewed to illustrate this topic.

\section{THE DIMERIZATION OF LIGHT OLEFINS}

The dimerization of light olefins by metal catalysts has been a widely studied [9-11] topic. 

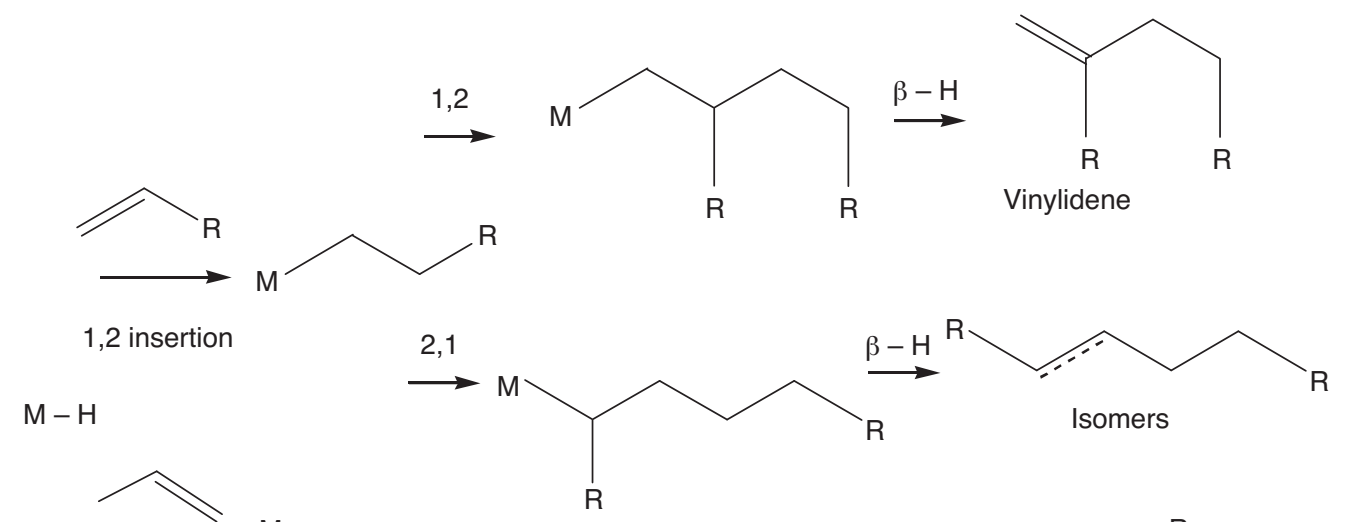

Scheme 1

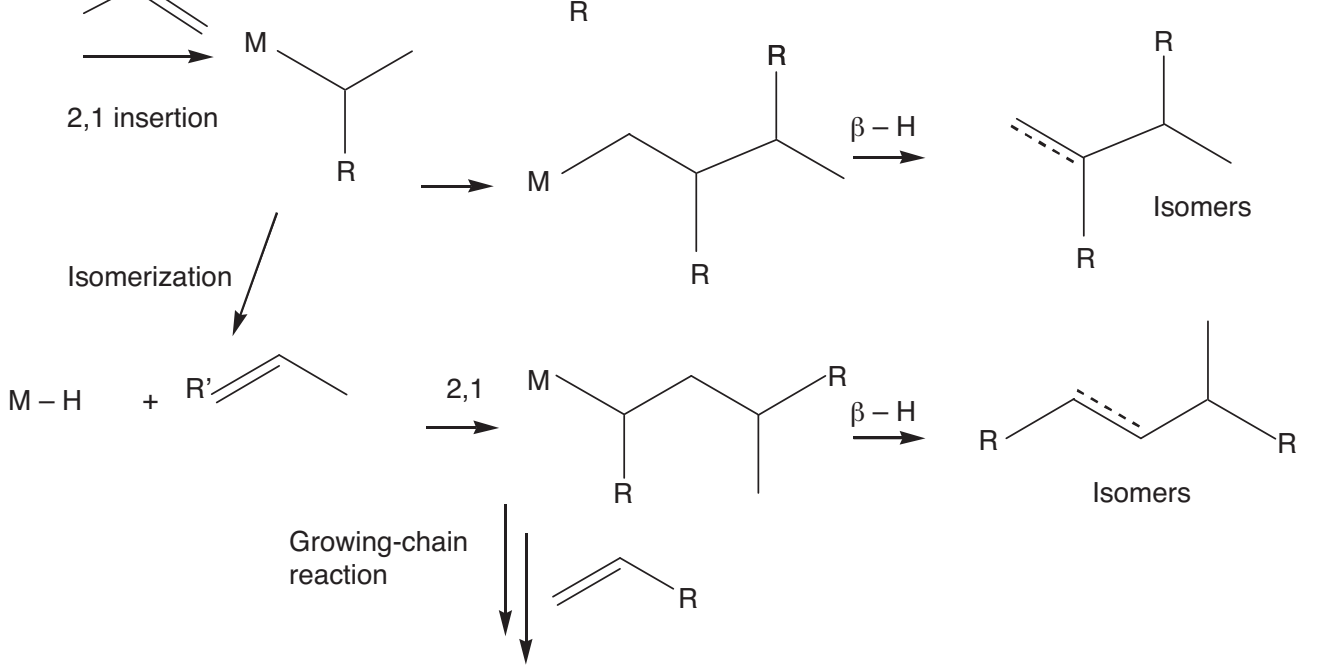

Trimer,

higher oligomers

Reaction pathways for the formation of the different dimer structures.

There are different pathways for the dimerization of alpha olefins and this reaction is generally non regioselective [12-14] (see Scheme 1). Most of the catalysts generate vinylidene dimers (2-alkyl-1-alkene) or dibranched dimers and are not selective for linear dimers. With these kind of catalytic systems, the challenge is to control consecutive reactions: reaction of dimers with monomers and dimer double bond isomerization. The formation of higher oligomers by these consecutive reactions can be limited by adjusting the monomer conversion. However, trimers and higher oligomers can also be formed by parallel growing chain reactions.

With some catalysts, particularly nickel catalysts, double bond isomerization occurs by insertion of the dimer in the metal hydride bond followed by $\beta-\mathrm{H}$ elimination. Butenes isomers (mainly 2-butenes) are produced [15] by ethylene dimerization catalyzed by bis(tri-n-butylphosphine)dichloronickel activated with an alkyl aluminium halide (ethyl aluminium dichloride) but it is not possible to produce selectively 1-butene [16] by this route.

\subsection{Non Regioselective Dimerization of Propene}

Nickel catalysts have given rise to numerous studies and are used on an industrial scale owing to their very high activity and their relative low cost. Most of the catalytic systems described in many publications and patents generate cationic complexes by different ways and a common active cationic nickel hydride species $(\mathrm{Ni}-\mathrm{H})^{+} \mathrm{A}^{-}$is invoked.

In the industrial Dimersol $\mathrm{G}^{\mathrm{TM}}$ process, the active catalyst is formed in situ by the reaction of a nickel (II) salt with an ethylaluminium chloro derivative. This catalytic system transforms propene into a mixture of dimers, trimers and tetramers of various structures. The average composition of the dimers shows little dependence on the temperature. At $50^{\circ} \mathrm{C}$, the isohexenes distribution by structure is: $22 \%$ of n-hexenes, $72 \%$ of 2 -methylpentenes and $6 \%$ of $2,3-$ dimethylbutenes.

Nonregioselective dimerization is widely used on an industrial scale for propene but also for n-butenes and also 


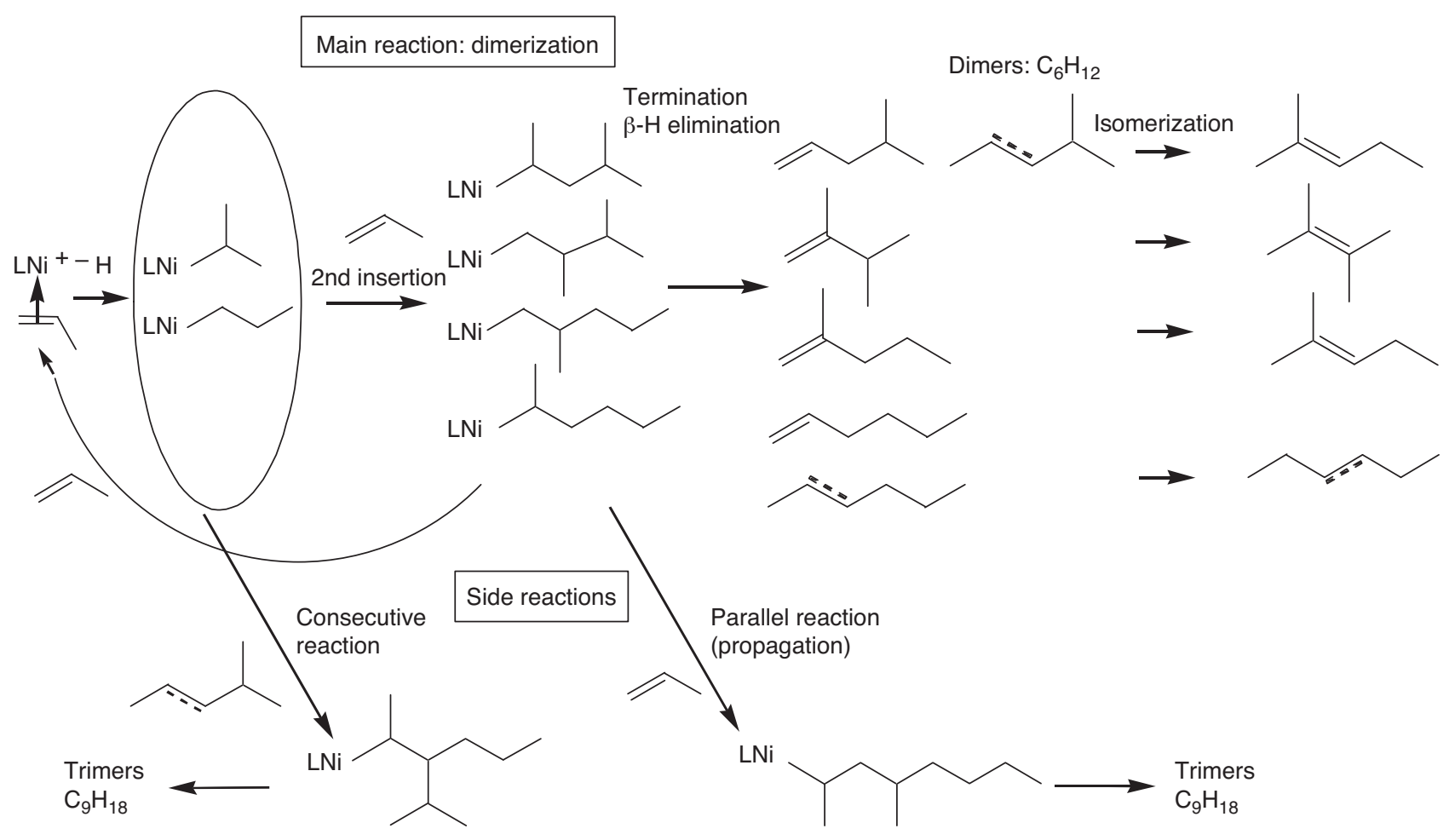

Scheme 2

Nonregioselective dimerization of propene catalyzed by cationic nickel complexes. General scheme for the formation of oligomers.

ethylene (IFP Dimersol ${ }^{\mathrm{TM}}$ Process cf. infra). The olefin reactivities decrease in the following order: ethylene $>$ propene $>$ n-butenes.

Olefin dimers are the major products due to the high rate of $\beta$-hydrogen abstraction but trimers and tetramers form by a parallel growing-chain reaction and also by consecutive reactions of dimers with monomer [17] (see Scheme 2 for propene dimerization). That is why, at high conversion of propene $(>80 \%)$, the selectivity to dimers depends on the type of reactor used.

\subsection{Regioselective Dimerizations of Propene}

\subsubsection{2,3-Dimethylbutenes with Ni-Catalyst}

Cationic nickel complexes are generally non selective, but addition of phosphines can have a considerable effect on the regioselectivity of propene dimerization as shown by Wilke et al. [18] with well defined cationic $\eta^{3}$-allylnickel complexes (Fig. 1). Bulky and basic phosphine ligands such as triisopropylphosphine or tricyclohexylphosphine favour the formation of 2,3-dimethylbutenes. 2,3-dimethylbutenes are especially important since they can be used as key starting olefins for fine chemical intermediates. 2,3-dimethyl2-butene is used for the synthesis of Danitol ${ }^{\mathrm{TM}}$, which is a high performance pyrethroid insecticide invented by Sumitomo in 1976, and to produce other intermediates (Pinacolone). 2,3-dimethyl-1-butene is a key intermediate for the production of musk fragrances (Tonalid ${ }^{\mathrm{TM}}$ ).

In the Sumitomo process, very high selectivities into dimethylbutenes in the $\mathrm{C}_{6}$ olefins (up to $85 \%$ ) are obtained at $20-50^{\circ} \mathrm{C}$ using a sophisticated Ziegler-type catalyst comprising tricyclohexylphosphine as ligand and toluene or chlorobenzene as solvent. Due to the close boiling points of

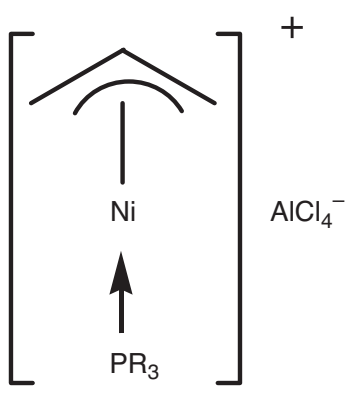

Figure 1 


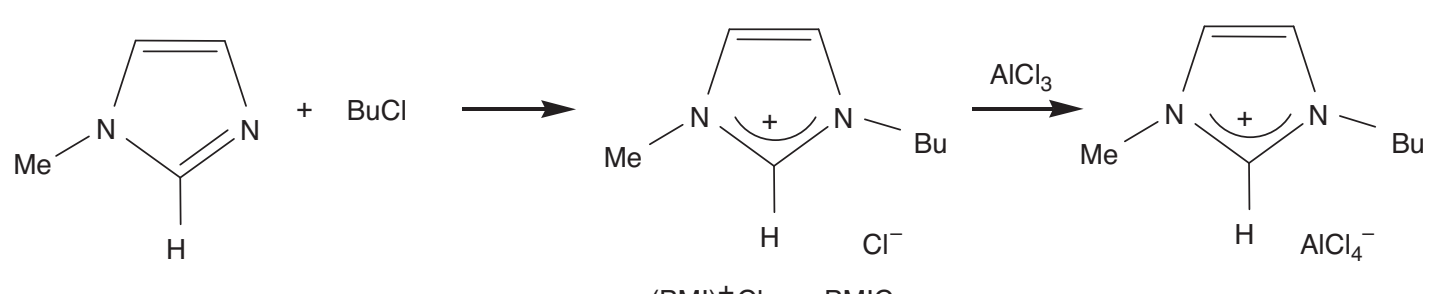

$(\mathrm{BMI})^{+} \mathrm{Cl}^{-}$or $\mathrm{BMIC}$

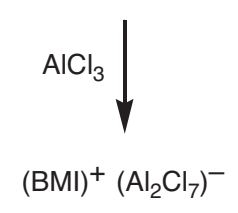

Scheme 3

Synthesis of acidic chloroaluminate ionic liquids.

the different isohexene isomers (Tab. 3), isomerization of 2,3-dimethyl-1-butene into 2,3-dimethyl-2-butene is achieved in the dimerization reactor and 2,3-dimethyl-2butene can be easily extracted by distillation. The active catalyst for isomerization is a Lewis acidic component resulting from the interaction between $\mathrm{AlEt}_{3}$ and a chlorinated phenol [19] present in the catalyst formula. When the chlorinated phenol is used at less than 1.5 moles per mole of $\mathrm{AlEt}_{3}$,2,3-dimethyl-1-butene can be produced without isomerization. An important increase in both the catalytic activity and the selectivity of dimers, upon addition of methanesulfonic acid or dimethyl sulfate to this catalytic system, was reported [20].

TABLE 3

Boiling points of isohexenes isomers

\begin{tabular}{c|c}
\hline & $\mathrm{Bp}\left({ }^{\circ} \mathrm{C}\right)$ \\
\hline 4-methyl-1-pentene & 53.87 \\
\hline 2,3-dimethyl-1-butene & 55.2 \\
\hline cis-4-methyl-2-pentene & 56.4 \\
\hline trans-4-methyl-2-pentene & 58.61 \\
\hline 2-methyl-1-pentene & 62.11 \\
\hline trans-3-hexene & 66.45 \\
\hline trans-2-hexene & 67.88 \\
\hline 2-methyl-2-pentene & 67.31 \\
\hline cis-2-hexene & 68.99 \\
\hline 2,3-dimethyl-2-butene & 73.21 \\
\hline
\end{tabular}

Several catalytic systems based on nickel and tricyclohexylphosphine, activated by chloroalkylaluminium compounds or methylaluminoxane have been published [21].
Due to the high cost of the phosphine ligand, liquid-liquid biphasic catalysis can be an interesting appproach to separate and recover the $\mathrm{Ni}$ phosphine catalytic system. The main issue is the choice of the most suitable catalyst solvent. Acidic chloroaluminate based ionic liquids proved to be the most promising [22] (Scheme 3). They act both as catalyst phase and nickel activator.

Providing a right adjustment of the chloroaluminate ionic liquid composition (aluminium chloride to imidazolium chloride), the same phosphine effect than in the homogeneous system can be obtained. The cationic nickel-phosphine active species is immobilized in the ionic phase without the need of designing special ligand. The liquid isohexenes form a second phase which can be easily separated from the ionic liquid catalytic phase by decantation. However, a dramatic decrease of the dimethylbutenes selectivity is observed after a few hours of the run. This can be explained by a competition for coordination of the phosphine between the "soft" Ni complex and the "hard" $\mathrm{AlCl}_{3}$ potentially present in the ionic liquid. This induces a decoordination of the phosphine from the nickel and a loss of the selectivity (Eq. 1).

$\left(\mathrm{PR}_{3} \cdot \mathrm{NiR}\right)^{+} \mathrm{A}^{-}+\mathrm{Al}_{2} \mathrm{Cl}_{7}^{-} \leftrightarrow(\mathrm{NiR})^{+} \mathrm{A}^{-}+\mathrm{AlCl}_{3} \cdot \mathrm{PR}_{3}+\mathrm{AlCl}_{4}^{-}$

The stabilization of the selectivity towards 2,3-dimethyl1-butene has been successively achieved by addition of small amounts of a weak organic Lewis base (noted B) such as a substituted aromatic hydrocarbon (Eq.2).

$\left(\mathrm{PR}_{3} \cdot \mathrm{NiR}\right)^{+} \mathrm{A}^{-}+\mathrm{Al}_{2} \mathrm{Cl}_{7}^{-}+\mathrm{B} \leftrightarrow\left(\mathrm{PR}_{3} \cdot \mathrm{NiR}\right)^{+} \mathrm{A}^{-}+\mathrm{AlCl}_{3} \cdot \mathrm{B}+\mathrm{AlCl}_{4}^{-}{ }^{-}(2)$

A new biphasic continuous flow process for the selective dimerization of propene producing 2,3-dimethyl-1-butene was disclosed [23] by IFP.

The selectivity towards 2,3-dimethyl-1-butene versus time, for a continuous flow propene dimerization reaction in chloroaluminates, is shown in Figure 2. These results demonstrate that it is possible to produce more than $5 \mathrm{~kg}$ of 2,3-dimethyl-1-butene with only $15 \mathrm{~mL}$ of ionic liquid. 


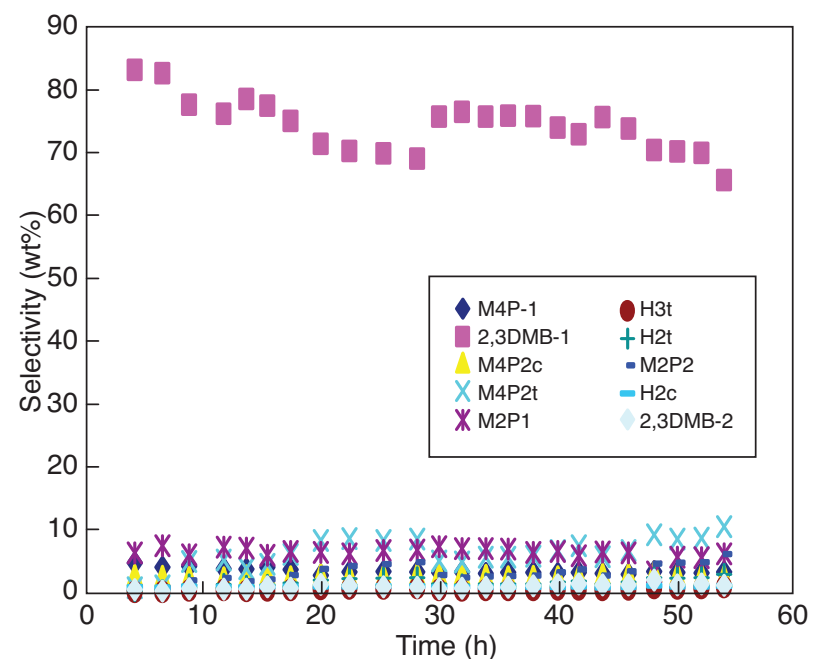

$15 \mathrm{~mL}$ ionic liquid; atmospheric pressure of propene, production of 11 liters of liquid products: $\mathrm{C}_{6}$ selectivity: $80-81 \%$ / total products; 2,3-DMB-1 selectivity: $70-75 \%$ / total $\mathrm{C}_{6}$;

M4P-1: 4-methyl-1-pentene; M4P2t: 4-methyl-2-pentene-trans; M4P2c: 4-methyl-2-pentenecis; M2P1: 2-methyl-1-pentene; H3t: 3-hexene-trans; H2t: 2-hexene-trans; H2c: 2-hexenecis, 2,3DMB-2: 2,3-dimethyl-2-butene.

\section{Figure 2}

Continuous flow dimerization of propylene in chloroaluminate ionic liquids - Hexenes distribution.

\subsubsection{2,3-Dimethylbutenes with Tungsten Catalyst}

Catalysts based on tungsten hexachloride and anilines [24], activated with ethylaluminium dichloride $(\sim 10$ mol. equiv. $)$ are reported to dimerize propene with high selectivities to 2,3-dimethylbutenes.

It may be suspected that the active species precursor is the monoimido W(VI) complex such as described in Equation (3).

$$
\mathrm{WCl}_{6}+\mathrm{ArNH}_{2} \rightarrow \mathrm{Cl}_{4} \mathrm{~W}=\mathrm{NAr}+2 \mathrm{HCl}
$$

Isolated organoimido tungsten complexes $\left(\mathrm{Cl}_{4} \mathrm{~W}=\mathrm{NAr}\right.$ with $\mathrm{Ar}=\mathrm{Aryl}$ ) catalyze the dimerization of propene in the presence of ethylaluminium dichloride in a similar way as the mixture $\mathrm{WCl}_{6} /$ aniline/Et $\mathrm{AlCl}_{2}$. With high $\mathrm{Al}$ to $\mathrm{W}$ ratio and sterically demanding arylimido groups (2,6-disubsti- tuted phenyl groups) tail to tail coupling of two moles of propene yielding 2,3-dimethylbutenes (75-85\%) is favored. These catalytic systems are also active with ethylene. Diethylaluminium chloride proved to be a better cocatalyst and a good selectivity toward formation of 1-butene was observed. The isolated complex $\mathrm{Cl}_{2} \mathrm{~W}=\mathrm{NPh}\left(\mathrm{PMe}_{3}\right)_{3}$ catalyzes the ethene dimerization when activated with $\mathrm{AlCl}_{3}$ $(\mathrm{Al} / \mathrm{W}=4.5)$. The formation of a metallacyclopentane intermediate [25] has been proposed to explain this selectivity but a strict proof remains elusive (Scheme 4). A DFT study centered on a metallacycle mechanism was recently published [26].

\subsubsection{4-Methyl-1-Pentene}

4-methyl-1-pentene is mainly used as co-monomer with linear low density polyethylene and for the production of poly-4-methyl-1-pentene (TPX), a high-quality polymer excellent in heat resistance, transparency and impact strength.

Using molecular transition metal complexes, two different mechanisms are possible for the formation of 4-methyl1-pentene: one involving a 2,1 insertion of propene into a metal hydride bond followed by another 2,1 insertion of propene and $\beta$-hydride elimination (Scheme 5), the other involves a $\beta$-methyl elimination after a 1,2 insertion of propene into a metal methyl bond followed by a 1,2 insertion of propene (Scheme 6).

In 1990 Teuben et al. [27] reported that ionic group 4 complexes $\left[\mathrm{Cp}_{2}{ }_{2} \mathrm{MMe}(\mathrm{THT})\right]^{+}\left(\mathrm{BPh}_{4}\right)^{-}(\mathrm{M}=\mathrm{Zr}, \mathrm{Hf}$, THT $=$ tetrahydrothiophene) oligomerize propene and that the hafnium compound gives mainly one dimer (4-methyl-1pentene: $72 \%$ ) and one trimer (4,6-dimethyl-1-heptene: $24 \%$ ). 3,3,3 Trideuteropropene was used to demonstrate that $\beta-\mathrm{Me}$ elimination is the dominant termination (Scheme 6).

In 1991 Yamazaki et al. [28] reported that $\mathrm{Cp}^{*}{ }_{2} \mathrm{MCl}_{2}$ $(\mathrm{M}=\mathrm{Zr}, \mathrm{Hf})$, in presence of methylaluminoxane (MAO), catalyzed the oligomerization of propene to produce mainly 4-methyl-1-pentene as well as other dimers, trimers and higher oligomers.

Recently, Okuda et al. [29] showed that the introduction of bulky substituents on the cyclopentadienyl ligands improve the selectivity of 4-methyl-1-pentene formation up

$$
\mathrm{Cl}_{2} \mathrm{~W}=\mathrm{NArL}_{3}+n \mathrm{AlCl}_{3}+2 \mathrm{CH}_{2}=\mathrm{CH}_{2} \rightarrow(n-1) \mathrm{AICl}_{3} \cdot \mathrm{L}+\left[\mathrm{CIW}=\mathrm{NArL}_{3-n}\left(\mathrm{C}_{2} \mathrm{H}_{4}\right)_{2}\right]^{+} \mathrm{AICl}_{4}^{-}
$$

Scheme 4 


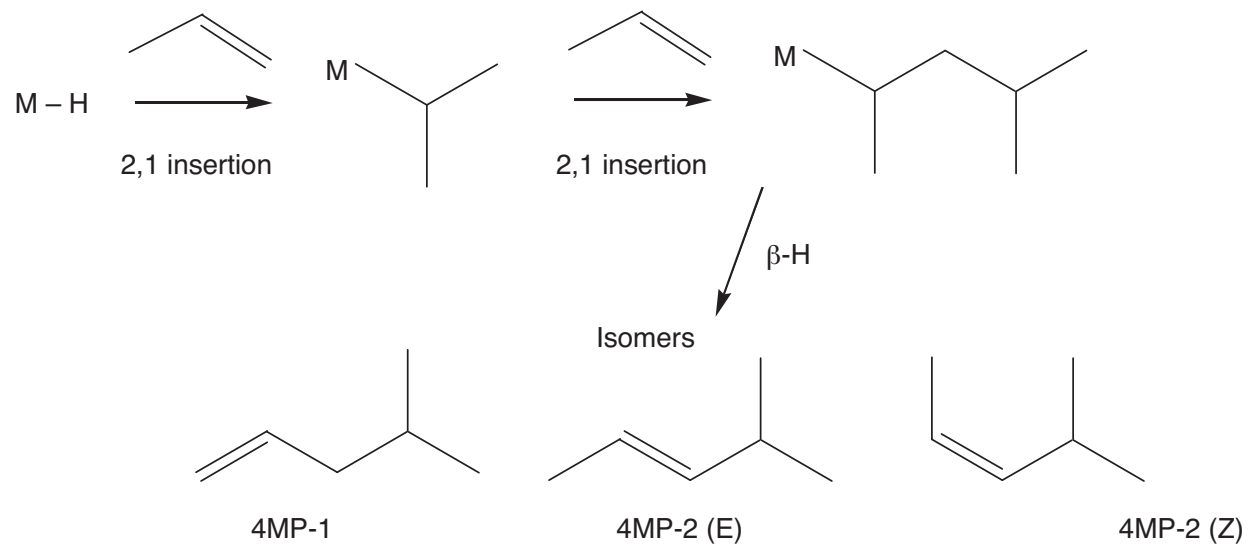

Scheme 5

Reaction pathway for the formation of 4-methyl-1-pentene ( $\beta$-hydride elimination).

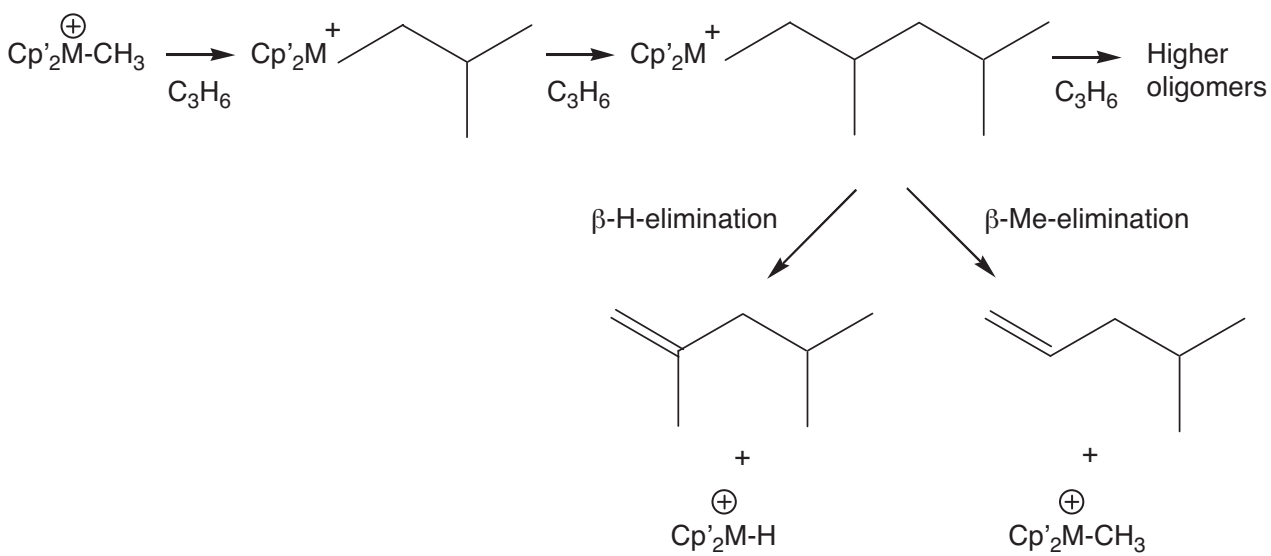

Scheme 6

Reaction pathway for the formation of 4-methyl-1-pentene by $\beta$-methyl elimination with $\mathrm{M}=\mathrm{Zr}$ or $\mathrm{Hf}$.

to $60 \%$ but other reaction pathways involving insertion of propene into a metal hydride bond followed by a second insertion of propene then a $\beta$-hydride elimination, a $\beta$-methyl elimination or chain growing produce considerable amounts of by products (dimers, trimers and also higher oligomers). The use of di(poly-substituted cyclopentadienyl)-allylic uranium (III) complexes, such as $\mathrm{Cp}^{*}{ }_{2} \mathrm{U}(2-$ methallyl), (Cp* $=$ pentamethylcyclopentadienyl), to catalyze the dimerization of propene to form 4-methyl-1-pentene selectively was also described [30].

So far, all these catalytic systems have not been selective enough because the $\beta$-methyl elimination step is not sufficiently predominant on the two other competing steps: $\beta$-hydride elimination or propagation (Scheme 6).

Some interesting results were obtained using the bisimino-pyridine iron catalytic systems [31]. The selectivity for 4-methyl-1-pentene remains low ( $30 \%$ of the dimers) because it is not possible to sufficiently control the propene insertion at each stage and finally the $\beta$-hydride elimination ( $\mathrm{Z}$ and $\mathrm{E}$ isomers of 4-methyl-2-pentene represents respectively $\sim 12 \%$ and $\sim 39 \%$ of the dimers) (Scheme 7 ). The substitution of the aryl groups of the imine ligand plays an essential role on directing the dimerization selectivity.

The application of the recent developments of homogeneous catalysts for the selective dimerization of alpha olefins to branched alpha olefins is limited and processes to produce 4-methyl-1-pentene are still based on propylene dimerization promoted by heterogeneous catalysts generated by dispersion of alkali metals (sodium or potassium) on potassium carbonate or other appropriate supports [32]. However it is difficult to maintain activity and selectivity at high levels for a very long period of time and some improvements of these type of heterogeneous catalyst have been disclosed [33]. 


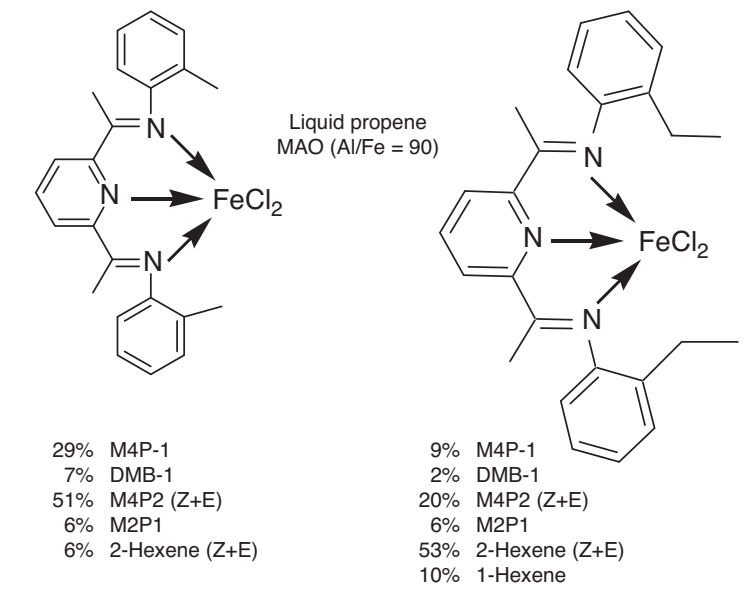

M4P-1: 4-methyl-1-pentene; M4P2: 4-methyl-2-pentene; M2P1: 2-methyl-1-pentene; DMB-1: 2,3-dimentyl-1-butene.

Scheme 7

Dimerization of propene with iron the bis-arylimino-pyridine catalysts. Effect of the aryl substitution on regioselectivity.

\subsection{Dimerization Catalysts Producing Vinylidene Olefins}

Among the catalysts that are selective for light olefin dimerization, most of them produce vinylidene (2-alkyl-1alkene) dimers. Cyclopentadienyl zirconium complexes activated by an aluminoxane [34] can produce selectively 2-alkyl-1-alkene (vinylidene dimers), for example 2-methyl1-pentene from propene with a selectivity close to $90 \%$.
Similarly, cationic bis cyclopentadienyl zirconium complexes can form selectively vinylidene dimers. For example, 1-pentene is converted into 2-propyl-1-heptene [35] with no isomerization of the excess of 1-pentene and bis cyclopentadienyl alkyl zirconium catalysts activated with an organoborane such as $\mathrm{B}\left(\mathrm{C}_{6} \mathrm{~F}_{5}\right)_{3}$ dimerize propene into 2-methyl-1-pentene or into a mixture of 2-methyl-1-pentene [36] and 2-methyl-2-pentene.

Some catalysts have the same head to tail regioselectivity but are less selective toward dimers, and higher oligomers are also produced. The formation of a Schulz-Flory distribution of 1-butene oligomers (dimers to heptamers) was reported for the catalytic system [37] ethylenebis (tetrahydroindenyl) zirconium dichloride/MAO.

\subsection{Catalysts with Improved Selectivity for Linear Dimers}

The formation of linear olefin dimers is the result of head-tohead coupling of alpha olefins. Starting from a metal hydride active species, the first step is a $(1,2)$ insertion of an alpha olefin to generate a primary alkyl species. It is followed by a $(2,1)$ insertion of the olefin in the metal alkyl bond then linear dimers isomers are formed by chain transfer $(\beta-\mathrm{H}$ elimination to metal or $\beta-\mathrm{H}$ transfer to monomer).

There is no catalyst known to produce only linear dimers from alpha olefins. For the best catalytic systems, the selectivity into linear dimers in the dimer fraction was generally less than $80 \%$ and these systems [38] based on non ionic nickel complexes containing chelating ligands like acetylacetonate generally exhibit low activity.
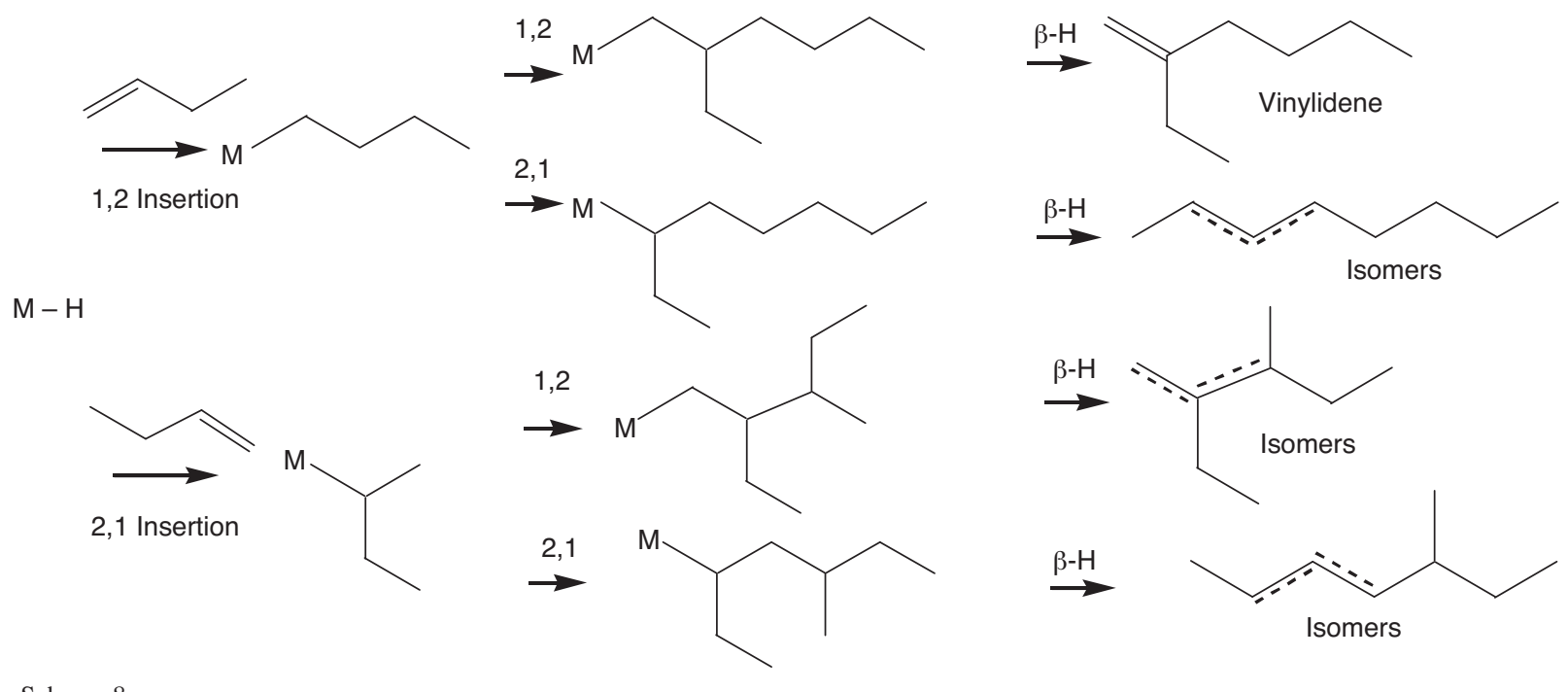

Scheme 8

Reaction pathway for 1-butene dimerization. 


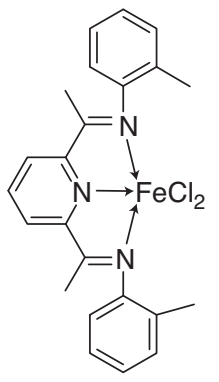

Figure 3

Bis-imino-pyridine iron complex used for 1-butene dimerization.

The acidity of the ligand is essential for a catalytic activity and best results are obtained with hexafluoro (or trifluoro) acetylacetone. The combination of high ligand cost and low activity has prevented industrial development.
The transformation of 1-butene into a mixture of octenes with good activities and a high selectivity for linear octenes [5] using bis(imino)pyridine iron complexes (Fig. 3) activated with methylaluminoxane (MAO) or modified methylaluminoxane (MMAO) was recently disclosed (Scheme 8: 57\% conversion of 1-butene, $85 \%$ dimers, $68 \%$ of which are linear octenes). For the dimerizartion of propene and 1-butene catalyzed by cobalt bis(imino)pyridine complexes, significant improvements in terms of activity and selectivity were reported using fluorinated iminopyridine ligands [39] (propene dimers: $72 \%$ with 1-hexene: $90 \%$, 2-hexenes: $9 \%$ ).

\section{ETHYLENE OLIGOMERIZATION}

Ethylene is a readily available feedstock, and its oligomerization represents the main source for alpha-olefins in industry. The oligomers possess exclusively an even number of carbon

TABLE 4

Industrial commercial processes for ethylene oligomerization to alpha-olefins ("full range processes")

\begin{tabular}{|c|c|c|c|c|}
\hline Industrial & Process name & Catalytic system & Product Characteristics & Technology characteristics \\
\hline Chevron Phillips & Gulfene & $\begin{array}{c}\mathrm{Al} \\
\text { Ziegler catalyst }\end{array}$ & $\begin{array}{c}\text { Schulz-Flory distribution } \\
\mathrm{C}_{4}-\mathrm{C}_{30^{+}} \\
K=0.5-0.75 \\
\text { little isomerization, } \\
\text { broad distribution } \\
\text { limited flexibility }\end{array}$ & $\begin{array}{l}\text { - single stage process } \\
\text { - low catalyst concentration } \\
\text { - no catalyst recovery } \\
\text { (Al destroyed by alkali } \\
\text { hydrolysis) }\end{array}$ \\
\hline Shell & SHOP & $\begin{array}{c}\mathrm{Ni} \\
\text { molecular complex } \\
(\text { Fig. } 4)\end{array}$ & $\begin{array}{l}\text { Schulz-Flory distribution } \\
\qquad \begin{array}{c}K=0.75-0.8 \\
\mathrm{C}_{6}-\mathrm{C}_{30}+\end{array}\end{array}$ & $\begin{array}{l}\text { - biphasic oligomerization } \\
\text { (1,4-butanediol as the solvent) } \\
\text { - isomerization } \\
\text { - metathesis }\end{array}$ \\
\hline Ineos & Ethyl & $\begin{array}{c}\mathrm{Al} \\
\text { Ziegler }\end{array}$ & $\begin{array}{l}\text { Poisson distribution } \\
\text { branched products }\end{array}$ & $\begin{array}{l}\text { - } 2 \text { separate steps: } \\
\text { - growth chain }\left(\mathrm{AlEt}_{3}\right) \text { low } \mathrm{T}^{\circ} \\
\quad\left(100-120^{\circ} \mathrm{C}\right) \\
\text { - displacement (high } \mathrm{T}^{\circ} \text { and } \\
\text { pressure) } \\
\text { - large quantity of catalyst } \\
\text { - recycling of low olefins } \\
\left(\mathrm{C}_{4}-\mathrm{C}_{8}\right)\end{array}$ \\
\hline Idemitsu & & $\begin{array}{c}\mathrm{Zr} \text { Ziegler-Natta } \\
\mathrm{Zr}+\mathrm{Et}_{3} \mathrm{Al}_{2} \mathrm{Cl}_{6}+\mathrm{AlEt}_{3} \\
\text { thiophene ligand }\end{array}$ & $\begin{array}{l}\text { Schulz-Flory distribution } \\
K \text { non disclosed }\end{array}$ & $\begin{array}{l}\text { - homogeneous system } \\
\text { cyclohexane as solvent [48a] }\end{array}$ \\
\hline \multicolumn{5}{|l|}{$\begin{array}{l}\text { Emerging commercial } \\
\text { processes }\end{array}$} \\
\hline IFP-Axens & Alphaselect & $\begin{array}{c}\text { Zr Ziegler-Natta } \\
\mathrm{Zr}+\text { ligand }+\mathrm{Al} \text { alkyl }\end{array}$ & \begin{tabular}{|}
$\operatorname{max~}_{\mathrm{C}_{4}-\mathrm{C}_{10}}$ \\
several distributions possible \\
$K$ factor can be adjusted \\
(for a given set of conditions, \\
a given $\mathrm{Zr} / \mathrm{Al}$ combination \\
directs the oligomerization to \\
a given distribution)
\end{tabular} & $\begin{array}{l}\text { - homogeneous catalysis } \\
\text { aromatic solvent [48b] }\end{array}$ \\
\hline$U O P$ & Linear-1 & $\begin{array}{c}\mathrm{Ni} \text { complex } \\
\mathrm{Ni}+\text { phosphine }\end{array}$ & $\begin{array}{c}\mathrm{C}_{4}-\mathrm{C}_{10} \\
K: 0.55-0.67\end{array}$ & - homogeneous system [49] \\
\hline Sabic & Alpha-Sablin & $\begin{array}{c}\text { Zr Ziegler-Natta } \\
\mathrm{Zr}+\mathrm{Al} \text { alkyl }\end{array}$ & $\begin{array}{c}\mathrm{C}_{4}-\mathrm{C}_{10} \text { and } \mathrm{C}_{4}-\mathrm{C}_{18} \\
K \text { non disclosed }\end{array}$ & - homogeneous system [48c] \\
\hline
\end{tabular}




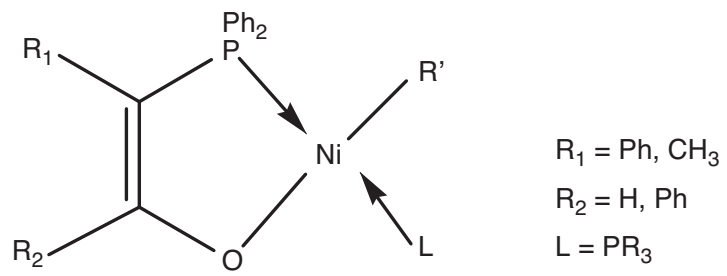

Figure 4

Molecular active Ni catalyst (SHOP process).

atoms and represent commercially valuable products $[10,11$, 8]. The production of alpha-olefins was initially realized by the "stoichiometric" Alfen process [40, 41], whereby the chain-growth reaction on aluminum was followed by the liberation of the product in a separate reactor at higher temperatures. A one step catalytic process was developed by Gulf (now Chevron Phillips), where both reactions occur simultaneously in the same reactor. The Ethyl process (now INEOS) is a combination of stoichiometic and catalytic chain-growth reactions $[8,41](T a b .4)$.

A remarkable catalytic system for the oligomerization of ethylene with selective formation of linear alpha-olefins is the Shell Higher Olefin Process (SHOP). Keim and coworkers [42] used the $\mathrm{Ni}(\mathrm{P}, \mathrm{O})\left(\mathrm{PR}_{3}\right) \mathrm{R}^{\prime}$ system, shown in Figure 4, for ethylene oligomerization.

Recent developments for the oligomerization of ethylene with nickel complexes containing chelating ligands were reviewed recently [43].

In contrast to the SHOP process, which is based on a molecular organometallic nickel complex, other systems for ethylene oligomerization or polymerization require ZieglerNatta type systems $e . g$. a transition metal associated with an alkylaluminum cocatalysts [10, 44, 45, 46, 47] (Eq. 4).

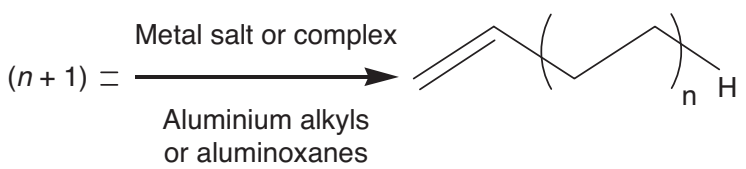

These catalytic systems generally afford a geometric Schulz-Flory distribution of olefins mainly by a metalhydride type mechanism (Scheme 9).

The repartition of the alpha olefins is determined by two competing reactions, chain growth (rate constant $k_{g}$ ) versus chain termination (rate constant $k_{t}$ ) and characterised by a $K$ value $\left(K=k_{g} /\left(k_{g}+k_{t}\right)\right)$.

Due to consecutive reactions of the alpha olefins with ethylene, increasing amount of branched olefins are obtained with increasing chain length.

Short chain linear alpha-olefins (1-butene, 1-hexene, 1-octene) are of particular interest because of their use for example as comonomers in the synthesis of linear low density polyethylene.

In the last twenty years, new processes operating with zirconium [48] or nickel [49] catalysts were developed, most of them trying to produce mainly $\mathrm{C}_{4}$ to $\mathrm{C}_{12}$ olefins in order to maximize the amount of alpha-olefins in the comonomer range.

\section{Development of Selective Oligomerization Catalytic Systems}

The development of efficient catalysts systems for the selective production of these olefins has triggered intensive research in both academia and industry. For this purpose, titanium [50] and chromium-based catalysts have attracted much attention [4]. Homogeneous chromium catalysts play a major role in ethylene trimerization [51] and tetramerization reactions $[4 \mathrm{~b}, 52]$.

$$
\begin{aligned}
& \text { (M) }-\mathrm{H} \stackrel{\mathrm{C}_{2} \mathrm{H}_{4}}{\rightleftarrows}(\mathrm{M})-\mathrm{C}_{2} \mathrm{H}_{5} \\
& \mathrm{C}_{2} \mathrm{H}_{4} \uparrow \\
& \text { (M) }-\mathrm{C}_{4} \mathrm{H}_{9} \stackrel{\mathrm{C}_{2} \mathrm{H}_{4}}{\rightleftarrows}
\end{aligned}
$$
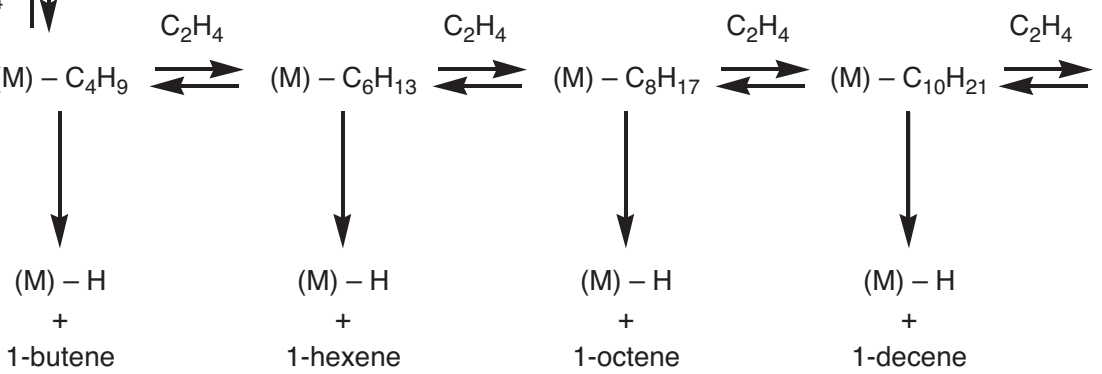
(M) $-\mathrm{H}$
$+$
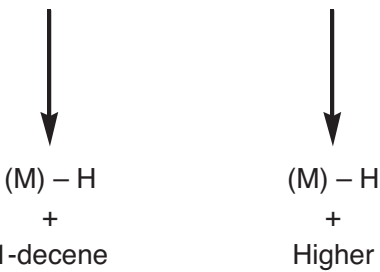

Geometric distribution of alpha olefins by a metal-hydride mechanism. 


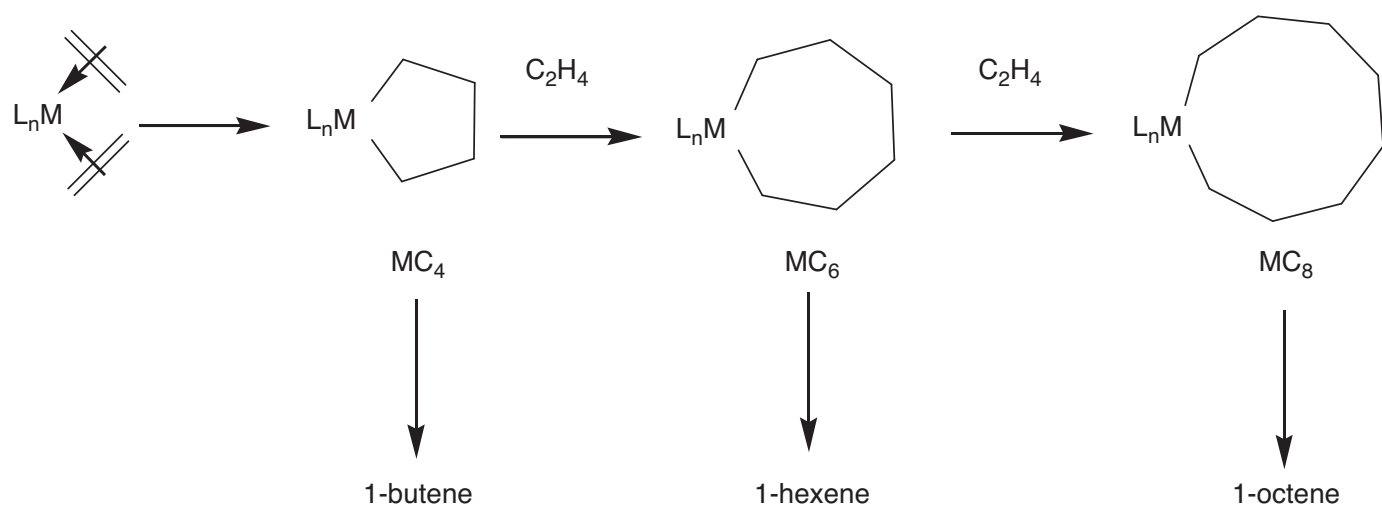

Scheme 10

Metallacyclic mechanism for selective ethylene oligomerization.

For titanium catalysts, selective dimerization of ethylene to 1-butene is well known [12] and occurs via a metallacyclic mechanism (see Schemes 10 and 11).

The observed selectivity in ethylene dimerization, trimerization or tetramerization reactions is a consequence of the metallacyclic mechanism in operation (Scheme 10). This non-Schulz-Flory-type of oligomerization process involves a two-electron redox couple (Ti(II)/Ti(IV) and probably $\mathrm{Cr}(\mathrm{I}) / \mathrm{Cr}(\mathrm{III}))$. Since polymerization generally accompanies, to variable extents, selective trimerization or tetramerization catalyzed by chromium complexes, the metal oxidation state responsible for each of these mechanistically distinct processes is an important topic of investigation [53].

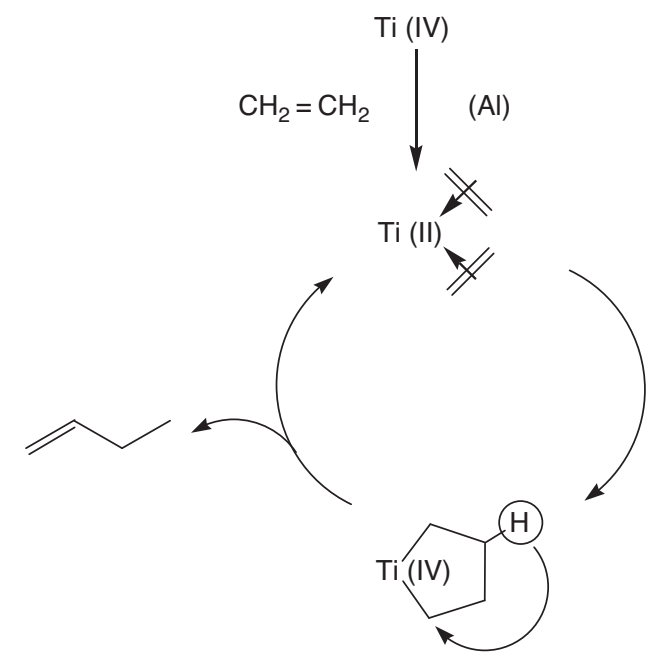

Scheme 11

1-Butene formation mechanism with the Alphabutol Catalyst.
The key to the selectivity of these systems appears to be the energetically preferred tendency of $\mathrm{MC}_{4}, \mathrm{MC}_{6}$ and $\mathrm{MC}_{8}$ metallacycles to undergo a product releasing $\beta$-hydrogen shift rather than further ethylene insertion. Bercaw and coworkers [54] demonstrated this metallacyclic mechanism, for a chromium catalyst, with a trimerization experiment involving a mixture of ethylene and deuterated ethylene, which leads to a 1-hexene isotopomer distribution of only $\mathrm{C}_{6} \mathrm{H}_{12}, \mathrm{C}_{6} \mathrm{H}_{8} \mathrm{D}_{4}, \mathrm{C}_{6} \mathrm{H}_{4} \mathrm{D}_{8}$, and $\mathrm{C}_{6} \mathrm{D}_{12}$. The absence of $\mathrm{H} / \mathrm{D}$ scrambling strongly indicates a metallacycle mechanism and is inconsistent with a Cossee-Arlman linear chain growth mechanism (non-redox polymerization-type mechanism).

In Scheme 10, we have limited the metallacyclic growth at the $\mathrm{MC}_{8}$ stage but the possibility of growth to large ring metallacycles leading to a distribution of higher olefins has been recently [55] reported and demonstrated by deuteriumlabelling studies.

The production of 1-hexene with titanium catalysts was recently realized by the development of a modified cyclopentadienyl system [56] (Fig. 5). The authors showed

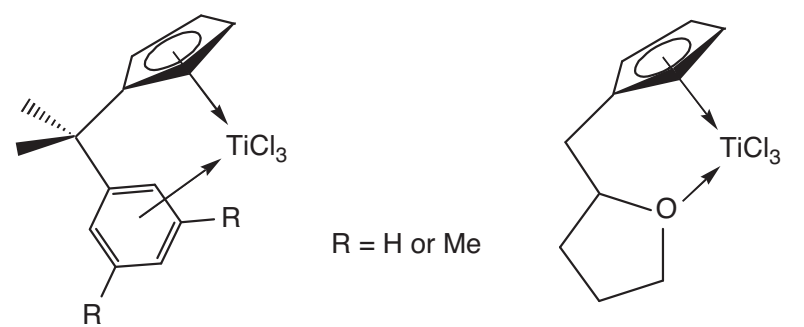

Figure 5

Modified Titanium catalyst precursors used for the selective ethylene trimerization. 


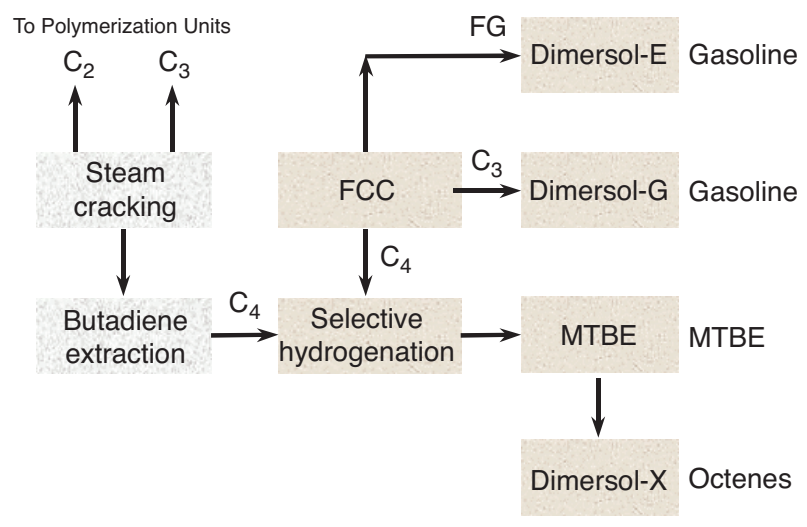

Figure 6

Upgrading Light Olefins fractions by oligomerization Dimersol processes.

that the addition of an aromatic side arm to a $\mathrm{Cp}$ ligand dramatically changes the selectivity of the known ethylene polymerization system $\left[\mathrm{CpTiCl}_{3}\right]-\mathrm{MAO}$. The main drawback of this catalyst is the requirement of a very high $\mathrm{MAO} / \mathrm{Ti}$ ratio.

\section{EXAMPLES OF INDUSTRIAL PROCESSES}

\subsection{The Dimersol Processes}

In 1965, dimerization and oligomerization of light olefins became the subject of intensive R\&D activity in IFP. In 1977, the first Dimersol plant was put on-stream in the
United States by Total Petroleum in Michigan (producing $50000 \mathrm{t} / \mathrm{y}$ of gasoline by dimerization and oligomerization of propylene from an $\mathrm{FCC} \mathrm{C}_{3}$ cut). The Dimersol technology is now used in three different processes, Dimersol-E ${ }^{\mathrm{TM}}$, Dimersol-G $\mathrm{G}^{\mathrm{TM}}$ and Dimersol- $\mathrm{X}^{\mathrm{TM}}$, depending on feedstock and desired product quality. Till now, 35 Dimersol units have been licensed corresponding to an overall processing capacity exceeding 4.5 million tons of feed per year.

Despite a planned restriction of olefin levels in gasoline in the U.S. and an increasing demand of propylene from FCC for petrochemistry, some Dimersol $\mathrm{G}^{\mathrm{TM}}$ are still in operation to produce octane booster additives for gasoline.

The Dimersol processes are offering an attractive alternative to upgrade olefinic light ends produced by Fluid Cracking or Steam Cracking processes and still satisfy the market requirements of motor-fuels or petrochemicals. The typical placement of Dimersol processes in refineries and petrochemical plants is shown in Figure 6.

The $\mathrm{C}_{2}$ cut extracted from high severity FCC fuel-gas appears as an excellent feed for a Dimersol E unit. Conversion of ethylene from Fischer-Tropsch unit is also an option to optimize the synthetic gazoline pool.

Despite an increasing demand for propylene extraction, $\mathrm{C}_{3}$ cut from FCC remains the prefered feed for a DimersolG unit producing and excellent high octane sulfur free gazoline base.

After selective hydrogenation of Steam Cracking $\mathrm{C}_{4}$ raffinates downstream of a butadiene extraction or FCC $\mathrm{C}_{4}$ cuts, the resulting $\mathrm{C}_{4}$ stream can be sent to an MTBE unit which separates isobutylene. The raffinate-2, sometimes after deisobutanization, may be upgraded in a Dimersol- $\mathrm{X}^{\mathrm{TM}}$ unit where the residual butenes are converted to high value octenes and dodecenes. The $\mathrm{C}_{8}$ olefins are used as precursors for oxoalcohols (Isononyl Alcohols) which are transformed

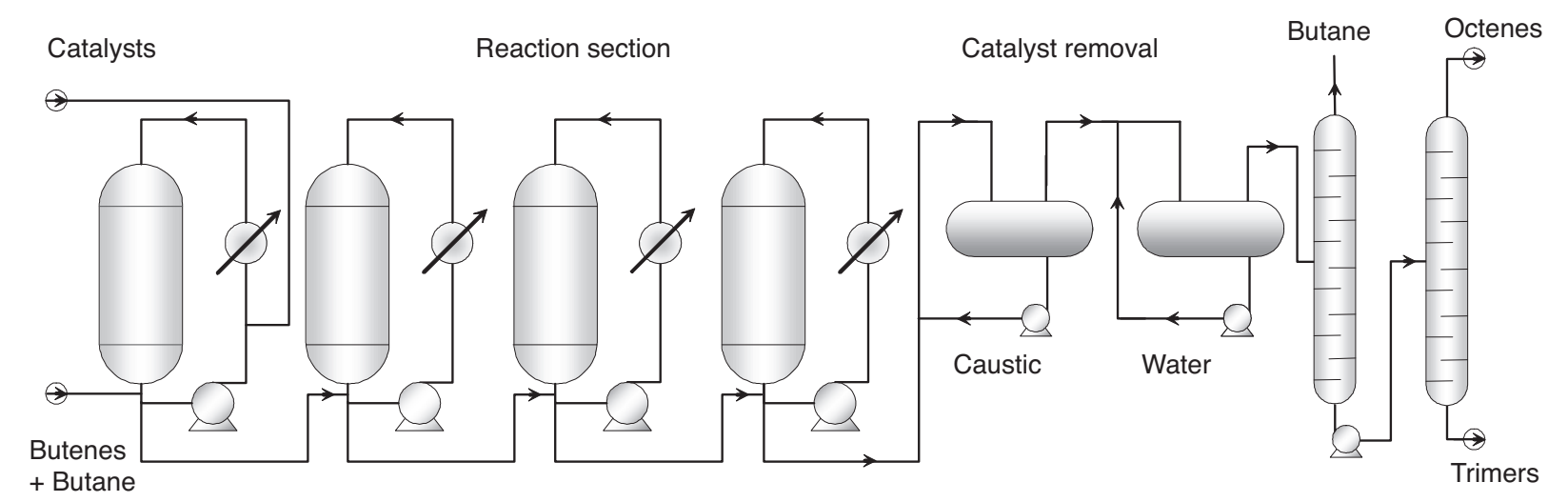

Figure 7

Dimersol Process Scheme. 
CATIONS
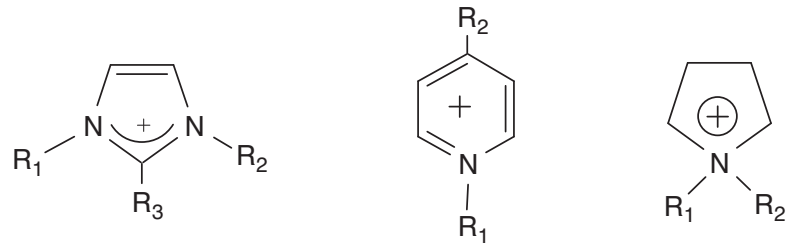

$\mathrm{R}_{1-3}=\mathrm{H}$, alkyl, cycloalkyl, aryl or aralkyl substituents

ANIONS

First generation

$\mathrm{AlCl}_{4}^{-}, \mathrm{Al}_{2} \mathrm{Cl}_{7}^{-}, \mathrm{Al}_{3} \mathrm{Cl}_{10}{ }^{-}$: water sensitive

$\mathrm{FeCl}_{4}^{-}, \mathrm{Fe}_{2} \mathrm{Cl}_{7}^{-}$
Second generation

$\mathrm{PF}_{6}^{-}, \mathrm{SbF}_{6}^{-}, \mathrm{BF}_{4}^{-}$

$\mathrm{CF}_{3} \mathrm{SO}_{3}^{-}, \mathrm{CF}_{3} \mathrm{CO}_{2}^{-},\left(\mathrm{CF}_{3} \mathrm{SO}_{2}\right)_{2} \mathrm{~N}^{-},\left(\mathrm{CF}_{3} \mathrm{SO}_{2}\right)_{3} \mathrm{C}^{-}$

Third generation: free of halide ions

$\mathrm{CH}_{3} \mathrm{CO}_{2}^{-}, \mathrm{C}_{6} \mathrm{H}_{5} \mathrm{SO}_{3}{ }^{-},(\mathrm{RO})_{2} \mathrm{PO}_{2}^{-}, \mathrm{PO}_{4}^{3-}, \mathrm{HSO}_{4}^{-}, \mathrm{RSO}_{4}^{-}, \mathrm{SO}_{4}{ }^{2-}, \mathrm{BR}_{4}^{-}, \mathrm{RCB}_{11} \mathrm{H}_{11}{ }^{-}$

Figure 8

Selected exemples of mostly used ionic liquids.

into diisononylphthalates (DINP) which are high value PVC plasticizers.

Dimersol- $\mathrm{X}^{\mathrm{TM}}$ can also process a mixture of $\mathrm{C}_{3}$ and $\mathrm{C}_{4}$ olefins to make dimers and co-dimers.

\subsubsection{The Dimersol Technology}

Despite the diversity of the feeds, all Dimersol processes are based on the same processing steps. The reaction section comprises one or more cascaded reactors. Feed is injected continuously into the first reactor, Figure 7 . The process takes place in the liquid phase using a soluble catalytic system at low pressure and mild temperature.

The catalyst system results from the reaction, in dilute medium, of two components: a catalyst precursor mixture containing a nickel organic salt and an aluminum-based co-catalyst. The two components produce the working Ziegler nickel hydride catalyst. The proprietary hydrocarbon-diluted nickel catalyst and aluminum-based co-catalyst are injected separately into the reaction loop under precise flow control. An external heat exchanger system enables accurate temperature control. To ensure complete separation of catalyst from the organic medium, the reactor effluent is chemically neutralized and the catalyst residue is removed from the hydrocarbon phase by aqueous washing in the neutralization section. A distillation column separates non-reactive hydrocarbons and unconverted olefins from oligomers.

The Dimersol- $\mathrm{X}^{\mathrm{TM}}$ process produces octenes by butenes dimerization. These octenes are mainly used as starting material for isononanols manufacture, which are then converted into dialkylphthalate plasticizers.
The Dimersol- $\mathrm{X}^{\mathrm{TM}}$ process scheme requires the same equipment with additional distillation enabling the separation of pure octenes and dodecenes.

The low degree of branching of these octenes has many advantages over the propylene or diisobutylene routes. Lowbranched octenes are the preferred feedstocks for producing nonanols by the oxonation reaction because, compared with the propylene route, the feed costs less and the plasticizers are of higher quality. Compared with nonanols produced using the diisobutylene route, the Dimersol- $\mathrm{X}^{\mathrm{TM}}$ allows a higher oxonation yield and produces better quality plasticizers.

\subsubsection{The New Difasol Liquid-Liquid Biphasic Technology in Ionic Liquid}

In the mid-1990s, research was initiated in one of the most promising recent areas in liquid phase catalysis: nonconventional, non-aqueous ionic liquids for biphasic catalysis. This technique employs a homogeneous catalyst dissolved in a liquid phase practically immiscible with the product, which enables easy separation of catalyst and organic products by simple phase decantation [57].

As a non-conventional class of solvent, non-aqueous ionic liquids are gaining importance in homogeneous catalysis. Previously, these media had been used extensively for electrochemical applications. Ionic liquids are only composed of ions. Although other cations have been extensively described in the literature, the most popular ones remain the dialkylimidazolium cations and particularly the 1-butyl-3-methylimidazolium or $\mathrm{BMI}^{+}$(Fig. 8).

The mixture of 1-Butyl-3-Methyl Imidazolium Chloride (BMIC) and aluminum chloride affords a liquid well below 


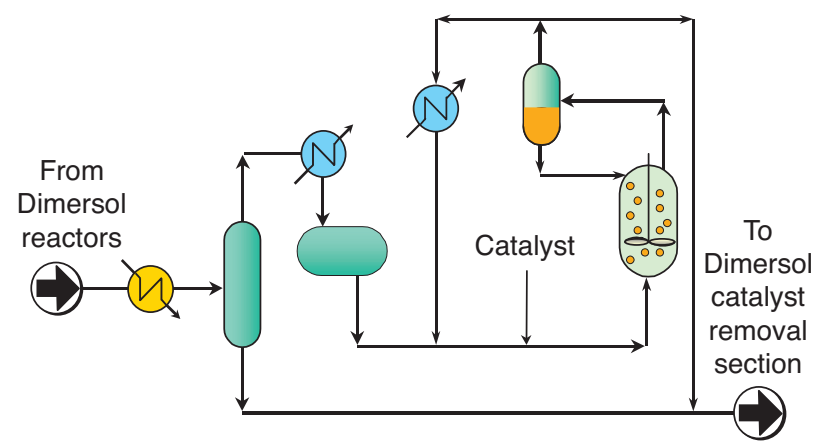

Figure 9

Biphasic Difasol section used as finishing step after a homogeneous Dimersol section.

room temperature and over a large range of compositions. These liquids proved to be good solvents for $\mathrm{Ni}$ catalyst for a variety of reasons:

- they are non-protic solvents and therefore compatible with the metal-carbon or metal-hydride bond active species;

- they are poorly miscible with hexenes, octenes and longer olefins (which, actually, is the first prerequisite to form a biphasic system) while propene and butenes solubility in ionic liquid is sufficient enough to stabilize the nickel active species and ensure high catalytic activity;

- chloroaluminates can easily be prepared from commercially available $\mathrm{N}$-alkylimidazole, alkylchloride and aluminium chloride;

- the chloroaluminate anions proved to be weakly coordinating toward nickel complex. Moreover, nickel active species is efficiently stabilized in the ionic medium, without the need of further modification;

- chloroaluminate ionic liquids could be extended to chloroalkylaluminium derivatives, the ionic liquids play both the role of solvent and co-catalyst;

- chloroaluminate ionic liquids can be turned acidic by adjusting the aluminium chloride amount.

Compared to the corresponding single-phase homogeneous process, the new biphasic process leads to a more economical utilization of the catalyst. New and existing Dimersol units can be fitted with Difasol enabling lower dimer production costs.

\section{Difasol Process: Dimersol Finishing Technology}

Dimersol- $X^{\mathrm{TM}}$, in its present commercial form, can achieve up to $80 \%$ of n-butenes conversion with $85 \%$ octenes selectivity. Unfortunately the butenes conversion level is dependent on their initial concentration in the Dimersol- $\mathrm{X}^{\mathrm{TM}}$ feedstock, limiting industrial applications to $\mathrm{C}_{4}$ cuts with a minimum butenes content of about $60 \%$.

This was a potential limitation to Dimersol- $\mathrm{X}^{\mathrm{TM}}$ yield until the Difasol technology became available. This new biphasic process promotes n-butenes dimerization even in poorly concentrated $\mathrm{C}_{4}$ cuts and is thus ideally suited as a Dimersol- $X^{\mathrm{TM}}$ finishing step (Fig. 9).

Effluent from the last Dimersol reactor is partly vaporized to separate unconverted $\mathrm{C}_{4}$ 's from octenes, heavy products and catalyst which are sent to the neutralization section. The vapor phase is totally condensed and sent to the Difasol reactor where the reaction occurs in liquid phase using the same nickel-based catalytic system as for the Dimersol process. The Difasol section consists of a stirred reactor that provides efficient mixing of the two liquid phases. The reactor outlet is sent to a settler where solvent and organic phases are separated. The solvent phase is returned to the reactor and a portion of the organic phase is recycled to the reactor through a cooler designed to remove the heat of reaction while the other part is sent to the neutralization section along with the effluent from the Dimersol reactors.

\section{Difasol Process Features}

Compared to conventional homogeneous Dimersol- $\mathrm{X}^{\mathrm{TM}}$ process, the biphasic system ensures more efficient catalyst utilization and reduces both residue production and operating cost. The dimer selectivity is higher, in the range of $90-95 \%$ compared to $85 \%$ in standard Dimersol $\mathrm{X}$ process. This is ascribed to the difference between the solubility of monomers and dimers in the ionic phase (Fig. 10). Improved butenes conversion (in the range of 70 to $80 \%$ ) are easily achieved in a single step even with diluted feedstocks.

Difasol is ideally suited for use as the finishing reaction section for a conventional Dimersol unit. This arrangement is applicable either for grassroots units or for revamping of existing Dimersol- $\mathrm{X}^{\mathrm{TM}}$ plants.

The use of Difasol technology also extends the field of application of the Dimersol processes to less reactive feeds

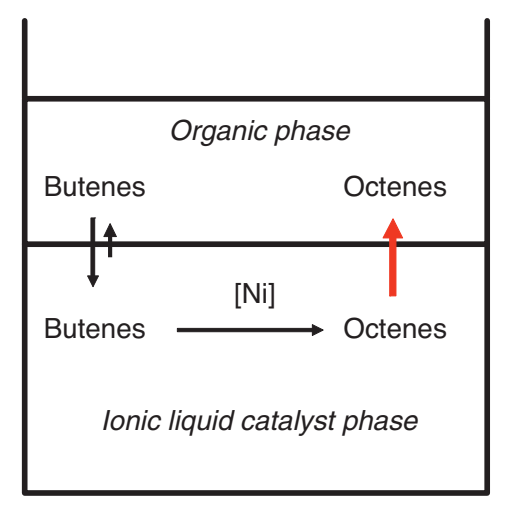

Figure 10

Schematic representation of biphasic catalysis in ionic liquids: improved selectivity for the dimers by a coupling of reaction and primary product separation. 


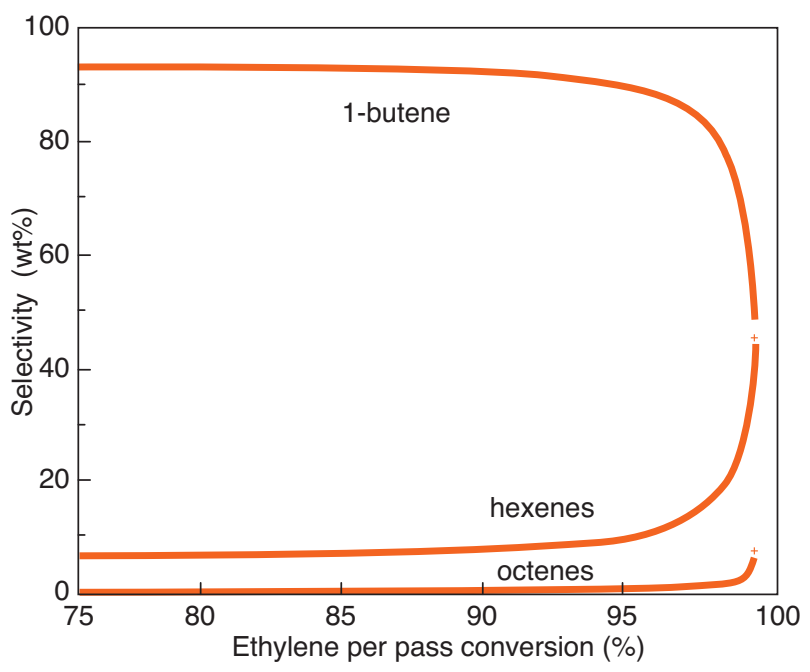

Figure 11

Impact of ethylene conversion on 1-butene selectivity.
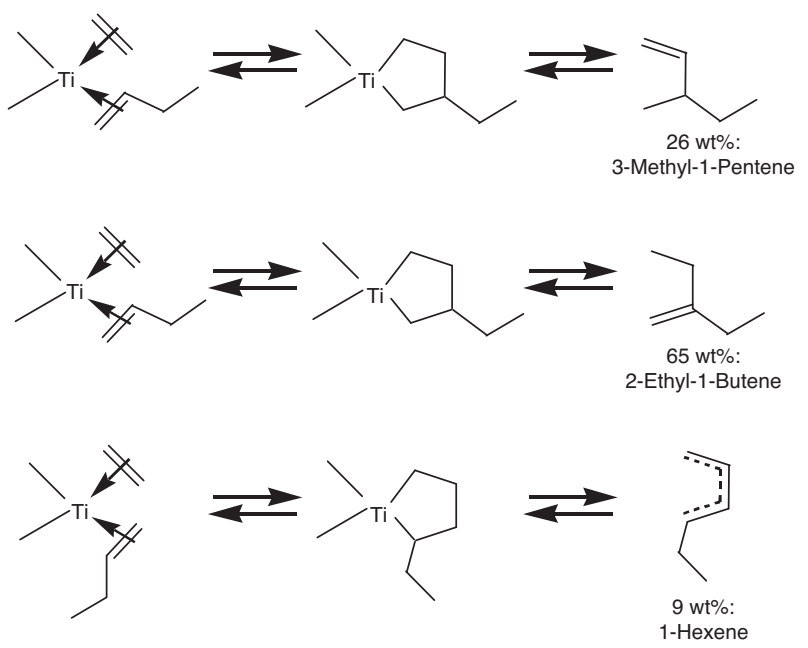

Scheme 12

Consecutive side reactions responsible for the ethylene trimers in the Alphabutol process. such as $\mathrm{C}_{5}$ olefins, allowing for the production of nonenes and decenes through co-dimerization of $\mathrm{C}_{4}$ and $\mathrm{C}_{5}$ olefins.

\subsection{The Alphabutol ${ }^{\mathrm{TM}}$ Process}

In 1981, a challenging project was launched: the production of 1-butene by selective dimerization of ethylene. An efficient soluble titanium-triethylaluminum complex was identified and rapidly tested in a pilot plant. In 1985, the commercial viability of the catalyst was proved and definitively established. The first Alphabutol unit was started up in 1986 in Thailand (TPIC, 3000 t/y), immediately followed by a much bigger plant for Sabic in Saudi Arabia (Petrokemya, 50000 t/y). Today, 24 Alphabutol units have been licensed, for a cumulated 1-butene production capacity of $500000 \mathrm{t} / \mathrm{y}$. Nearly $25 \%$ of the world's 1 -butene consumption as co-monomer in PE units is currently produced by Alphabutol technology.

The Alphabutol catalyst results from the reaction in the reaction medium of two components: a catalyst precursor mixture containing a titanium-based active metal and a cocatalyst diluted in 1-butene. Both components are separately injected into the reaction loop and react in situ to produce the catalyst. The principle catalytic step involves the coupling of two molecules of ethylene on the active titanium center to form a titanium (IV) heterocycle which then decomposes to 1-butene by an intra-molecular $\beta$ hydrogen transfer as shown in Scheme 11. This chemical mechanism explains the high dimer selectivity. The absence of hydride species ensures low isomerization from 1 to 2-butenes, and less than $100 \mathrm{ppm}$ of internal butenes is achieved.
A very minor amount of disproportionation produces n-butane $(<1500 \mathrm{ppm})$ and butadiene $(<10 \mathrm{ppm})$, the latter being immediately converted to hexadienes. The production of higher molecular weight oligomers is minimized by adjusting the per pass conversion. In industrial plants the per-pass conversion is generally limited to about 80 to $85 \%$. When conditions are optimized, 1-butene selectivity can attain 93\%, Figure 11.

In this process, 1-butene is not highly reactive by itself, but it can react with ethylene, giving hexene isomers (Scheme 12). This is typically a consecutive-type reaction which depends on the level of ethylene conversion. The rate constant of the main reaction is much higher than the one of the trimerization. Therefore it is possible to minimize oligomer production by adjusting the ethylene conversion (Fig. 11).

The Alphabutol process, Figure 12, was developed in cooperation with Sabic to produce high purity 1-butene by ethylene dimerization. Directly derived from the Dimersol E technology, (bubble point reactor operated under temperature and pressure controls) the process operates in the liquid phase using a soluble catalyst system.

Polymer grade ethylene is dissolved into the reaction medium. The metal-based catalyst and the co-catalyst, both diluted in 1-butene, are continuously injected in the reaction loop. The unit is designed to ensure uniform distribution of the catalyst components without local over-concentration.

Ethylene concentration in the reaction loop is simply monitored by pressure control (flash reactor operated at its bubble point). 


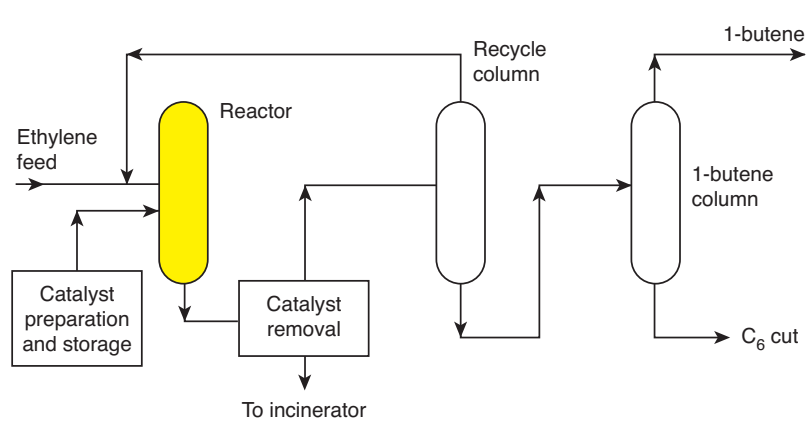

Figure 12

The Alphabutol Process.

Dimerization takes place in the liquid phase at mild conditions (typically $50-55^{\circ} \mathrm{C}$ ) and under controlled catalyst and ethylene concentrations. The exothermic heat of reaction is removed by external cooling. No specific solvent is required since the reaction takes place directly in the reactant-products mixture. The reactor effluent leaves the reaction loop for a spent catalyst separation system. The spent catalyst is removed and transformed into a non-toxic material before disposal. The hydrocarbon portion is vaporized and sent to the distillation section. The first distillation column separates unconverted ethylene, which is recycled to the reaction section. The second column recovers high purity 1-butene and $\mathrm{a}_{6}+$ gasoline cut.

The Alphabutol process exhibits a major advantage if compared with any other industrial sources of 1-butene available on the open market: its steady high quality of 1-butene, Table 5. This enables to minimize the ethylene purge in dowstream polyethylene unit.

TABLE 5

Alphabutol 1-butene characteristics

\begin{tabular}{c|c}
\hline 1-butene & $99.5 \% \mathrm{~min}$ \\
\hline butane & $<1500 \mathrm{ppm}$ \\
\hline 2-butenes & $<200 \mathrm{ppm}$ \\
\hline $\mathrm{C}_{6}$ olefins & $<100 \mathrm{ppm}$ \\
\hline
\end{tabular}

\section{Advantages of Alphabutol Over Competing Routes}

\section{to 1-Butene Production}

1-Butene is available in the $\mathrm{C}_{4}$ fractions from naphta crackers, but its recovery at a high purity level involves a sophisticated scheme. Among the various possible schemes, the most commonly used is the first to either extract or selectively hydrogenate butadiene, then to completely remove isobutene through MTBE synthesis at high conversion, followed by the separation of 1-butene from the other $\mathrm{C}_{4}$ 's either by super fractionation or by molecular sieves.
This processing scheme has the important drawback of being expensive in investment and operating cost compared to the Alphabutol route. To be economically viable, this scheme needs a local outlet for butadiene and MTBE. This favourable situation may hold for highly industrialized countries, mainly the USA, Japan and Europe, but it is not often the case in other countries. For a petrochemical company, the MTBE co-production can be problematic due to the recent MTBE ban in several locations.

A difficult market for these associated products or the lack of $\mathrm{C}_{4}$ cut in case of ethane crackers, lead LLDPE manufacturers to envisage ethylene dimerization by Alphabutol for 1-butene production.

\subsection{The AlphaSelect ${ }^{\mathrm{TM}}$ Process}

The AlphaSelect process, developped in IFP's facilities in the beginning of the 90 's, is oriented toward the production of high purity, linear alpha-olefins $\left(\mathrm{C}_{4}\right.$ to $\left.\mathrm{C}_{10}\right)$ that can be used as ethylene co-monomers for LLDPE production. These olefins can also be used as precursors for plasticizer alcohols, organic acids or higher molecular weight poly-alpha-olefins.

This new technology, very similar to the industrially proven Alphabutol process, operates in the liquid phase using a proprietary soluble catalytic system. Polymer grade ethylene is dissolved in the reaction medium. The oligomerization reaction takes place in the presence of a solvent system, at moderate operating temperature and pressure $\left(70-90 \mathrm{bar}, 130-150^{\circ} \mathrm{C}\right)$. The solvent maintains the higher molecular weight co-products soluble and enhances the catalyst activity. The catalyst and co-catalyst are diluted in the same solvent and are continuously injected in the reaction loop. The oligomerization takes place under controlled catalyst/co-catalyst ratio, ethylene/solvent ratio and of course ethylene concentration. The catalyst/co-catalyst ratio is a key parameter that enables the modification of the molecular weight distribution of the linear alpha-olefins.

The reaction mechanism is different from that found with the Alphabutol catalyst. AlphaSelect employs a different active center and a metal hydride complex , represented by $[\mathrm{M}]-\mathrm{H}$, is probably the actual in situ catalyst (Scheme 9). Alpha-olefin oligomers follow a geometric Schulz-Flory distribution which is affected by the aluminum-to-metal ratio. Alpha-olefins from AlphaSelect are also of very high quality (see Tab. 6); however, in this process, since multiple additions of ethylene are required, purity does decrease with increasing molecular weight. The impurities which make up the remaining balance of the AlphaSelect streams are composed of slightly branched and linear internal olefins.

AlphaSelect is highly selective, up to $93 \mathrm{wt} \%$, toward $\mathrm{C}_{4}$ $\mathrm{C}_{10}$ alpha-olefins. The product slate that is available with this process is one of its attractive features. The alpha-olefin distribution can be adjusted to obtain distributions that may vary with market demand, Table 7 . 
TABLE 6

Characteristics of the $\alpha$-olefins produced

\begin{tabular}{c|c}
\hline AlphaSelect olefins & $\alpha$-olefin purity (wt\%) \\
\hline 1-butene & 99 \\
\hline 1-hexene & 98 \\
\hline 1-octene & 96 \\
\hline 1-decene & 92 \\
\hline
\end{tabular}

TABLE 7

AlphaSelect $\mathrm{C}_{4}-\mathrm{C}_{10}$ olefin production flexibility

\begin{tabular}{c|c}
\hline AlphaSelect olefins & Distribution (wt\%) \\
\hline 1-butene & $35-40$ \\
\hline 1-hexene & $29-30$ \\
\hline 1-octene & $19-21$ \\
\hline 1-decene & $11-14$ \\
\hline
\end{tabular}

As with the Alphabutol process, the catalyst results from the reaction of two components diluted in the reaction medium. The catalyst precursor is freshly prepared in a preparation vessel near the reactor to ensure maximum activity. The precursor has a stability of a few weeks once freshly prepared.

The reactor effluent leaves the reaction loop for a spent catalyst separation system, Figure 13 . The spent catalyst is removed and oxidized to a non-toxic form and is stored for disposal. The hydrocarbon portion is vaporized and sent to the distillation section. The first distillation column separates the unconverted ethylene which is directly recycled to the reactor. A following distillation section enables the separation of pure 1-butene, 1-hexene, 1-octene and 1-decene product streams. The solvent is purified in the separation

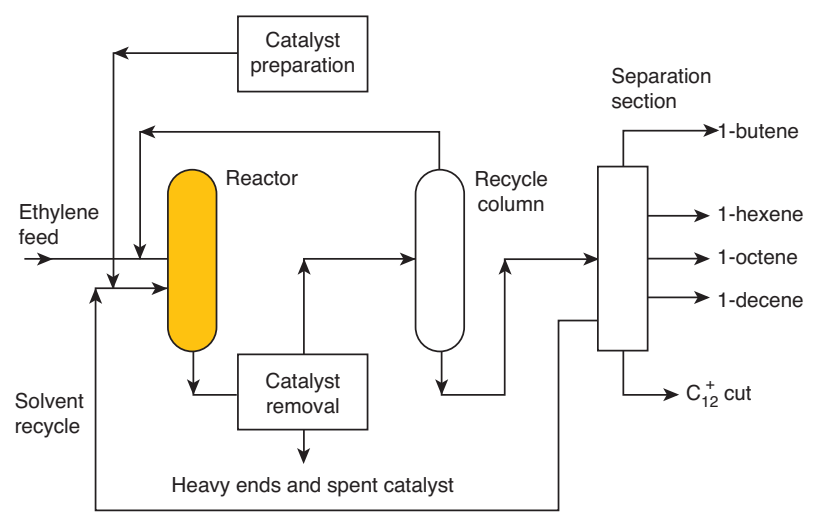

Figure 13

The AlphaSelect process section and recycled to the reactor. The $\mathrm{C}_{12}+$ oligomers are withdrawn from the fractionation bottom and from which valuable higher olefins can also be recovered.

\section{Common Key Process Features}

Both Alphabutol and AlphaSelect are characterized by their process simplicity. They employ carbon steel equipment and exhibit high turndown operations. Both processes are easy to operate and can produce high quality ethylene comonomers nearby polyethylene production units. The comparative economics of these processes are indicated in Table 8, below.

The Alphabutol process ensures a reliable, local source of steady, high purity 1-butene nearby the polyethylene unit.

AlphaSelect provides a flexible yield of $\mathrm{C}_{4}$ to $\mathrm{C}_{10}$ alphaolefins and allows in-situ comonomers production for modern multi grade LLDPE units.

TABLE 8

Comparative Alphabutol and AlphaSelect economics

\begin{tabular}{|c|c|c|}
\hline & $\begin{array}{c}\text { Alphabutol } \\
(30000 \mathrm{t} / \mathrm{y} \\
\text { 1-butene })\end{array}$ & $\begin{array}{c}\text { AlphaSelect } \\
(100000 \mathrm{t} / \mathrm{y} \\
\left.\mathrm{C}_{4}-\mathrm{C}_{10} \text { alpha-olefins }\right)\end{array}$ \\
\hline $\begin{array}{l}\text { Battery limits erected } \operatorname{cost}^{(1)} \text {, } \\
10^{6} \text { U.S.\$ }\end{array}$ & 14 & 80 \\
\hline Raw material ${ }^{(2)}$ - Ethylene, tons & 1.1 & 1.22 \\
\hline By-products ${ }^{(2)}$, tons & $\begin{array}{l}\mathrm{C}_{6}{ }^{+} \text {cut: } 0.08 \\
\text { Fuel gas: } 0.02\end{array}$ & $\begin{array}{c}\mathrm{C}_{12}{ }^{+} \text {olefins: } 0.14 \\
\text { Fuel gas: } 0.04 \\
\text { Heavy ends: } 0.04\end{array}$ \\
\hline Utilities $\operatorname{Cost}^{(3)}, \$ / t$ of product & 27 & 173 \\
\hline $\begin{array}{l}\text { Catalyst \& Chemical } \operatorname{Cost}^{(3)} \text {, } \\
\$ / t \text { of product }\end{array}$ & 27 & 30 \\
\hline
\end{tabular}

(1) 2007 Gulf Coast Basis, excluding licensor fees and detailed engineering.

(2) Expressed in tons per ton of 1-butene (Alphabutol) or $\mathrm{C}_{4}-\mathrm{C}_{10} \alpha$-olefins (AlphaSelect).

(3) Expressed in U.S.\$ per ton of 1-butene (Alphabutol) or $\mathrm{C}_{4}-\mathrm{C}_{10} \alpha$-olefins (AlphaSelect).

Recently IFP has completed the development of a new process able to produce selectively pure 1-hexene from ethylene. This new process is based on a proprietary chromium catalyst. Twenty years' experience of Alphabutol industrial applications has been integrated in this new technology to provide polymer grade purity 1-hexene close to a polyethylene unit.

\section{CONCLUSION}

During the last twenty years, the development of new ligands has been essential for the improvement of olefin oligomerization catalysts. Homogeneous catalysts allow good flexibility in the processes. Their high activity at low 
concentration level (ppm) enables to limit costs resulting from catalyst consumption and spent catalyst disposal. Progress have been made by finding more active and more selective catalysts and also by the development of two-phase catalytic processes.

The lighter linear alpha-olefins such as 1-butene, 1-hexene and 1-octene are predominantly produced by metal-catalyzed oligomerization of ethylene, which usually leads to a distribution of alpha-olefins with different chain lengths that frequently does not match the market demand. Now, 1-butene, 1-hexene can be produced by selective dimerization or trimerization of ethylene.

The production of these high purity olefins with these new on purpose processes has several advantages over other sources of supply: better and more steady product quality, a small amount of by-products, and a feedstock normally available at a polyethylene plant site.

According to recent progress, the extension of selective oligomerization route to the production of 1-octene and perhaps 1-decene seems possible.

\section{REFERENCES}

1 Catani R., Mandreoli M., Rossini S., Vaccari A. (2002) Catal. Today 75, 125-131.

2 Schmidt R., Welch M.B., Randolph B.B. (2008) Energ. Fuel.22, 1148-1155.

3 Deckers P.J., Hessen B.J., Teuben H. (2001) Angew. Chem. Int. Edit. 40, 2516-2519.

4 a) Dixon J.T., Green M.J., Hess F.M., Morgan D.H. (2004) J. Organomet. Chem. 689, 23, 3641-3668. b) Bollmann A., Blann K., Dixon J.T., Hess F.M., Killian E., Maumela H., McGuinness D.S., Morgan D.H., Neveling A., Otto S., Overett M., Slawin A.M.Z., Wasserscheid P., Kuhlmann S. (2004) J. Am. Chem. Soc. 126, 45, 14712-14713.

5 Small B.L., Marcucci A.J. (2001) Organometallics 20, 57385744.

6 Gibson V.C., Redshaw C., Solan G.A. (2007) Chem. Rev. 107, 1745-1776.

7 Bianchini C., Giambastiani G., Guerrero Rios I., Mantovani G., Meli A., Segarra A.M. (2006) Coordin. Chem. Rev. 250, 1391-1418.

8 Lappin G.R., Sauer J.D. (1989) Alphaolefins Applications Handbook, Marcel Decker Inc., Berkeley, CA.

9 Pillai S.M., Ravindranathan M., Sivaram S. (1986) Chem. Rev. 86, 353-399.

10 Skupinska J. (1991) Chem. Rev. 91, 613-648.

11 Al-Jarallah A.M., Anabtawi J.A., Siddiqui M.A.B., Aitani A.M., Al-Sa'doun (1992) Catal. Today 14, 1-121.

12 Chauvin Y., Olivier H. (1996) Applied Homogeneous Catalysis with Organometallic Compounds, Cornils B., Hermann W.A. (eds.), VCH, New York, Vol. 1, pp. 258-268.

13 a) Threlkel R.S., Kurkov V.P., Woo G.L. (1993) Chevron Research and Technology Company, US Pat. 5196 624. b) Threlkel R.S., Kurkov V.P. (1993) Chevron Research and Technology Company, US Pat. 5196625.

14 Mitkova M., Tomov A., Kurtev K. (1996) J. Mol. Catal. AChem. 110, 25-32.
15 a) Carter C. (1980) Phillips Petroleum Co., US Pat. 4242531. b) Carter C. (1985) Phillips Petroleum Co., US Pat. 4538018.

16 Al-Sherehy F.A. (1996) Stud. Surf. Sci. Catal. 100, 515-523.

17 Pruvot A., Commereuc D., Chauvin Y. (1983) J. Mol. Catal. 22, 179-185.

18 Wilke G., Bogdanowitch B., Hardt P., Heimbach O., Kroner W., Oberkirch W., Tanaka K., Steinrucke E., Walter D., Aimmerman H. (1966) Angew. Chem. Int. Edit. Engl. 5, 151.

19 a) Sato H., Noguchi T., Yasui S. (1993) B. Chem. Soc. Jpn 66, 3069-3078. b) Sato H., Tojima H. (1993) B. Chem. Soc. Jpn 66, 3079-3084.

20 a) Nomura K., Ishino M., Hazama M., Suzukamo G. (1997) J. Mol. Catal. A-Chem. 126, L93-L97. b) Itagaki M., Suzukamo G., Nomura K. (1998) B. Chem. Soc. Jpn 71, 79-82.

21 a) Anon. (1990) BP Chemicals, Chem. Brit. 26, 400. b) Carlini C., Marchionna M., Raspolli Galletti A.M., Sbrana G. (2001) J. Mol. Catal. 169, 19-25. c) Cavell K.J. (1993) J. Chem. Soc. Dalton 59-68.

22 Chauvin Y., Einloft S., Olivier H. (1995) Ind. Eng. Chem. Res. 34, 4, 1149-1155.

23 Olivier Bourbigou H., Pellier E., Forestière A. (2007) A. French Pat. Fr 2895406.

24 a) Menapace H.R., Maly N.A., Wang J.L., Wideman L.G. (1975) J. Org. Chem. 40, 2983-2985. b) Hendriksen D.E. (1991) Exxon Chemical, US Pat. 5059739.

25 Olivier H., Laurent-Gerot P. (1999) J. Mol. Catal. A-Chem. 148, 43-48.

26 Tobisch S. (2007) Organometallics 26, 6529-6532.

27 Eshuis J.J.W., TanY.Y., Renkema J., Teuben J.H. (1990) J. Mol. Catal. 62, 277-287.

28 Mise T., Kageyama A., Miya S., Yamazaki H. (1991) Chem. Lett. 1525-1528.

29 a) Suzuki Y., Yasumoto T., Mashima K., Okuda J. (2006) J. Am. Chem. Soc. 128, 13017-13025. b) Okuda J., Suzuki Y. (2008) US Pat. 2008/0281139.

30 Stevens J.C., Fordyce W.A. (1992) Dow Chemical, US Pat. 5 081231.

31 Babik S.T., Fink G. (2003) J. Organomet. Chem. 683, 209-219.

32 a) Pines H., Stalick W.M. (1977) Base catalyzed reactions of hydrocarbons and related compounds, Academic Press, pp. 205239. b) Hambling J.K. (1969) Chem . Brit. 5, 354. c)Pis'man I.I., Dalin M.A., Ansheles V.R., Vasil'kovskaya G.V., Vavilova I.I. (1968) Dolk. Akad. Nauk. SSSR 179, 608.

33 Kawazaki M., Kudoh M., Imai H. (1985) Nippon Oil, US Pat. 4 533781.

34 a) Slaugh L.H., Schoenthal G.W. (1987) Shell, US Pat. 4658 078. b) Wu F.-J. (1992) Ethyl, US Pat. 5087788.

35 van der Heijden H., Hessen B., Orpen A.G. (1998) J. Am. Chem. Soc. 120, 1112-1113.

36 Yang X., Stern C.L., Marks T.J. (1994) J. Am. Chem. Soc. 116, 10015-10031.

37 Kaminsky W. (1995) Macromol. Symp. 89, 203-219.

38 a) Ellis B., Keim W., Wasserscheid P. (1999) Chem. Commun. 337-338. b) Beach D.L., Bozik J.E., Wu C.-Y., Kissin Y.V. (1986) J. Mol. Catal. 34, 345-354.

39 Tellmann K.P., Gibson V.C., White J.P., Williams D.J. (2005) Organometallics 24, 280-286.

40 Ziegler K. (1952) Entdeckung der Aufbaureaktio, Brennst.Chem.35, 193. 
41 Vogt D. (1996) Applied Homogeneous Catalysis with Organometallic Compounds, Cornils B., Hermann W.A. (eds.), VCH, New York, Vol. 1, pp. 245-258.

42 Keim W. (1990) Angew. Chem. Int. Edit. 29, 235-244.

43 a) Kuhn P., Sémeril D., Matt D., Chetcuti M.J., Lutz P. (2007) Dalton Trans. 515-528. b) Speiser F., Braunstein P., Saussine L. (2005) Accounts Chem. Res. 38, 784-793.

44 Britovsek G.J.P., Gibson V.C., Wass D.F. (1999) Angew. Chem. Int. Edit. 38, 428-447.

45 Ittel S.D., Johnson L.K., Brookhart M. (2000) Chem. Rev. 100, 1169-1204.

46 Mecking S. (2001) Angew. Chem. Int. Edit. 40, 534-540.

47 Gibson V.C., Spitzmesser S.K. (2003) Chem. Rev. 103, 283-316.

48 a) Yamada T., Shiraki Y., Takeuchi K., Tamura T. (1994) Sekiyu Gakkaishi 37, 4, 337-346. b) Olivier H., Chodorge J.A., Travers P. (Autumn 1999) PTQ, p. 147. c) European Chemical News, 5-11 November 2001, p. 27.

49 ECN Chemscope, May 1998, pp. 24-26.

50 Commereuc D., Chauvin Y., Gaillard J., Léonard J., Andrews J. (1984) Hydrocarb. Process. 118-120.

51 a) Briggs J.R. (1989) J. Chem. Soc. Commun. 674. b) Reagen W.K., Conroy B.K. (1997) Phillips Petroleum Company, EP 0416304. c) Lashier M.E., Freeman J.W., Knudsen R.D. (1996) Phillips Petroleum Company, US 5543 375. d) Wu F.J. (1993) Ethyl corporation, EP 0537609. e) Uchida K., Ito Y., Iwanaga K. (1997) Sumitomo Chemical Company, EP 614865. f) Oshiki T., Aoshima T., Kawashima R., Iwade S. Nakamura H., Katsuki S., Okano T. (1994) Mitsubishi Kasei Corporation, EP 0611743. g) Jolly P.W. (1996) Accounts Chem. Res. 29, 544-551. h) Emrich R., Heinemann O., Jolly P.W., Kruger C., Verhovnik G.P.J. (1997) Organometallics 16, 1511- 1513. i) Commereuc D., Drochon S., Saussine L. (2002) IFP Fr 2.802.833, US 6828269. j) Yoshida T., Yamamoto T., Okada H., Murakita H. (2002) Tosoh Corporation, US 2002/0035029. k) Mimura H., Oguri M., Yamamoto T., Murakita H., Okada H. (2002) Tosoh Corporation, US 6337 297. 1) Wass D.F. (2002) BP Chemicals Ltd, WO 02/ 04119. m) Carter A., Cohen S.A., Cooley N.A., Murphy A., Scutt J., Wass D.F. (2002) Chem. Commun. 858. n) Dixon J.T., Wasserscheid P., McGuinness D.S., Hess F.M., Maumela H., Morgan D.H., Bollmann A. (2003) Sasol
Technology (Pty) Ltd, WO 03053890, WO 03053891. o) McGuinness D.S., Wasserscheid P., Keim W., Hu C., Englert U., Dixon J.T., Grove J.J.C. (2003) Chem. Commun. 334. p) McGuinness D.S., Wasserscheid P., Keim W., Morgan D.H., Dixon J.T., Bollmann A., Maumela H., Hess F.M., Englert U. (2003) J. Am. Chem. Soc. 125, 5272. q) Agapie T., Day M.W., Henling L.M., Labinger J.A., Bercaw J.E. (2006) Organometallics 25, 2733-2742. r) Schofer S.J., Day M.W., Henling L.M., Labinger J.A., Bercaw J.E. (2006) Organometallics 25, 2743-2749.

52 a) Blann K., Bollmann A., Dixon J.T., Neveling A., Morgan D.H., Maumela H., Killian E., Hess F.M., Otto S., Pepler L., Mahomaed H.A., Overett M.J. (2004) Sasol Technology (Pty) Ltd, WO 2004/056479. b) Overett M.J., Blann K., Bollmann A., Dixon J.T., Haasbroek D., Killian E., Maumela H., McGuinness D.S., Morgan D.H. (2005) J. Am. Chem. Soc. 127, 10723. c) Jabri A., Crewdson P., Gambarotta S., Korobkov I., Duchateau R. (2006) Organometallics 25, 715. d) Albahily K., Ko E., AlBaldawi D., Savard D., Gambarotta S., Burchell T.J., Duchateau R. (2008) Angew. Chem. Int. Edit. 47, 5816-5819.

53 Albahily K., Al-Baldawi, D. Gambarotta S., Koç E., Duchateau R. (2008) Organometallics 27, 5943-5947.

54 a) Agapie T., Schofer S.J., Labinger J.A., Bercaw J.E. (2004) J. Am. Chem. Soc. 126, 1304-1305. b) Agapie T., Labinger J.A., Bercaw J.E. (2007) J. Am. Chem. Soc. 129, 14281-14295.

55 a) Tomov A.K., Chirinos J.J., Jones D.J., Long R.J., Gibson V.C. (2005) J. Am. Chem. Soc. 127, 10166-10167. b) Tomov A.K., Chirinos J.J., Long R.J., Gibson V.C., Elsegood M.R.J. (2006) J. Am. Chem. Soc. 128, 7704-7705.

56 a) Deckers P.J.W., Hessen B., Teuben J.H. (2001) Angew. Chem. Int. Edit. 40, 2516-2519. b) Deckers P.J.W., Hessen B., Teuben J.H. (2002) Organometallics 21, 5122-5135. c) Hessen B. (2004) J. Mol. Catal. A-Chem. 213, 129-135.

57 a) Pârvulescu, V.I., Hardacre C. (2007) Chem. Rev. 107, 26152665. b) Zhang, Z.C. (2006) Adv. Catal. 49, 153-237. c) Olivier-Bourbigou, H., Magna L. (2002) J. Mol. Catal. A Chem. 182-183, 419-437.

Final manuscript received in April 2009 Published online in September 2009 or distributed for profit or commercial advantage and that copies bear this notice and the full citation on the first page. Copyrights for components of this work owned by others than IFP must be honored. Abstracting with credit is permitted. To copy otherwise, to republish, to post on servers, or to redistribute to lists, requires prior specific permission and/or a fee: Request permission from Documentation, Institut français du pétrole, fax. +33147527078 , or revueogst@ifp.fr. 